Article

\title{
The Impact of Reduction Temperature and Nanoparticles Size on the Catalytic Activity of Cobalt-Containing BEA Zeolite in Fischer-Tropsch Synthesis
}

\author{
Karolina A. Chalupka ${ }^{1, *}$, Jacek Grams ${ }^{1}{ }^{\circledR}$, Pawel Mierczynski ${ }^{1}{ }^{\oplus}$, Malgorzata I. Szynkowska ${ }^{1}(\mathbb{D}$, \\ Jacek Rynkowski ${ }^{1}$ (D) Thomas Onfroy $^{2}$, Sandra Casale ${ }^{2}$ and Stanislaw Dzwigaj ${ }^{2, *(1)}$ \\ 1 Institute of General and Ecological Chemistry, Lodz University of Technology, Zeromskiego 116, \\ 90-924 Lodz, Poland; jacek.grams@p.lodz.pl (J.G.); pawel.mierczynski@p.lodz.pl (P.M.); \\ malgorzata.szynkowska@p.lodz.pl (M.I.S.); jacek.rynkowski@p.lodz.pl (J.R.) \\ 2 Laboratoire de Réactivité de Surface, Sorbonne-Université-CNRS, UMR 7197, F-75005 Paris, France; \\ thomas.onfroy@sorbonne-universite.fr (T.O.); sandra.casale@sorbonne-universite.fr (S.C.) \\ * Correspondence: karolina.chalupka@p.lodz.pl (K.A.C.); stanislaw.dzwigaj@sorbonne-universite.fr (S.D.); \\ Tel.: +48-42-631-31-25 (K.A.C.); +33-1-44-27-21-13 (S.D.)
}

Received: 15 April 2020; Accepted: 9 May 2020; Published: 16 May 2020

check for updates

\begin{abstract}
A goal of this work was to investigate the influence of the preparation procedure and activation conditions (reduction temperature and reducing medium: pure hydrogen $\left(100 \% \mathrm{H}_{2}\right)$ or hydrogen-argon mixture $\left.\left(5 \% \mathrm{H}_{2}-95 \% \mathrm{Ar}\right)\right)$ on the activity of Co-containing BEA zeolites in Fischer-Tropsch synthesis. Therefore, a series of CoBEA zeolites were obtained by a conventional wet impregnation ( $\left.\mathrm{CO}_{5.0} \mathrm{AlBEA}\right)$ and a two-step postsynthesis preparation procedure involving dealumination and impregnation steps ( $\left.\mathrm{CO}_{5.0} \mathrm{SiBEA}\right)$. Both types of zeolites were calcined in air at $500{ }^{\circ} \mathrm{C}$ for $3 \mathrm{~h}$ and then reduced at 500, 800 and $900{ }^{\circ} \mathrm{C}$ for $1 \mathrm{~h}$ in $100 \% \mathrm{H}_{2}$ and in $5 \% \mathrm{H}_{2}-95 \%$ Ar mixture flow. The obtained Red-C-Co ${ }_{5.0} \mathrm{AlBEA}$ and Red-C-Co ${ }_{5.0} \mathrm{SiBEA}$ catalysts with various physicochemical properties were tested in Fischer-Tropsch reaction. Among the studied catalysts, Red-C-C ${ }_{5.0} \mathrm{SiBEA}$ reduced at $500{ }^{\circ} \mathrm{C}$ in pure hydrogen was the most active, presenting selectivity to liquid products of $91 \%$ containing mainly $C_{7}-C_{16}$ n-alkanes and isoalkanes as well as small amount of olefins, with CO conversion of about $11 \%$. The Red-C-CO5.0AlBEA catalysts were not active in the Fischer-Tropsch synthesis. It showed that removal of aluminum from the BEA zeolite in the first step of postsynthesis preparation procedure played a key role in the preparation of efficient catalysts for Fischer-Tropsch synthesis. An increase of the reduction temperature from 500 to 800 and $900{ }^{\circ} \mathrm{C}$ resulted in two times lower $\mathrm{CO}$ conversion and a drop of the selectivity towards liquid products (up to $62 \%-88 \%$ ). The identified main liquid products were n-alkanes and isoalkanes. The higher activity of Red-C-Co ${ }_{5.0} \mathrm{SiBEA}$ catalysts can be assigned to good dispersion of cobalt nanoparticles and thus a smaller cobalt nanoparticles size than in the case of Red-C-Co ${ }_{5.0} \mathrm{AlBEA}$ catalyst.
\end{abstract}

Keywords: $\mathrm{Co} ; \mathrm{BEA} ; \mathrm{CO} ; \mathrm{H}_{2}$; Fischer-Tropsch synthesis

\section{Introduction}

Fischer-Tropsch synthesis (FTS), developed in 1923, is an important process of alternative fuel production from $\mathrm{H}_{2}-\mathrm{CO}$ syngas derived from the conversion of biomass, coal and natural gas. Recently, there has been renewed interest in FTS due to the shrinkage of natural sources of conventional crude oil, as well as stringent environmental legislations concerning the quality of fuel and norms concerning exhaust gases emissions. One of the main aims of industrial and academic researchers has become the 
development of technology allowing the production of ultra-clean, sulfur-, nitrogen- and aromatic-free liquid fuels with a high octane number.

Among the large number of heterogeneous catalysts studied in FTS, cobalt supported systems are the most potent catalysts known [1]. Cobalt catalysts have shown high activity in the synthesis of long chain hydrocarbons because of their high selectivity to paraffin and low efficiency of water gas shift [2]. Evidence presented in many papers suggests that the size and nature of the Co species are fundamental properties responsible for catalytic activity [3]. Great effort is being made to find correlations between the catalyst's crystallinity, dispersion of Co nanoparticles, preparation methods, and efficiency in FTS.

The iron and cobalt $\left(\mathrm{Fe}\right.$ and $\mathrm{Co} / \mathrm{SiO}_{2}, \mathrm{Fe}$ and $\mathrm{Co} / \mathrm{Al}_{2} \mathrm{O}_{3}$ ) catalysts commonly used in FTS lead to the formation of linear hydrocarbons and n-paraffins (waxes) which have a high cetane but low octane number. For this reason, it seems justified to use high-silicon zeolites as catalyst carriers in the FTS process. These materials, due to their properties such as developed specific surfaces and the presence of micro- and meso-pores, can improve the metal dispersion inside the micro- and meso-porous channels and allow the formation of small metal nanoparticles. The well-known catalytic properties of zeolites in the cracking process are responsible for the reduction of the selectivity towards the formation of long chain paraffins. This may cause the increase of the octane number as a result of increasing the selectivity towards the formation of saturated and unsaturated short chain hydrocarbons which can form during processes occurring at acidic zeolite centers, such as the cracking of hydrocarbons containing more than 13 carbon atoms in the molecule, isomerization and aromatization of short chain olefins [4-8].

For several years, the activity of $\mathrm{Co}$ and $\mathrm{Fe}$ catalysts supported on various porous materials, such as: MCM-41, SBA-15, ZSM-5, ZSM-11, ZSM-12, ZSM-34, zeolite Y, ITQ-6, ITQ-2, $\beta$ zeolite and mordenite have been studied $[4-7,9,10]$. It was noted that the dispersion and average cobalt particle size depended on the pore size of the mesoporous material. Larger metal particles are formed on the surface of the support which was characterized by wider mesopores such as SBA-15. The reduction of this system was easier, and it was characterized by higher activity and lower selectivity to methane than the cobalt catalyst supported on MCM-41, which has a narrower pore size. A similar relation was also observed for a series of Co catalysts supported on commercial amorphous silica, differing only in pore diameter $\left(\mathrm{Co} / \mathrm{SiO}_{2}\right)$. During these studies it was found that the optimal average pore size of the support which can provide the high activity and selectivity to $C_{5_{+}}$hydrocarbons is $10 \mathrm{~nm}$. Catalytic systems with similar cobalt content supported on ordinary amorphous silica oxide $\left(\mathrm{SiO}_{2}\right)$ and SBA-15 material were also compared. It was noted that the Co/SBA-15 catalyst showed much higher activity than the $\mathrm{Co} / \mathrm{SiO}_{2}$ and the reason of this phenomenon was the fact that mesoporous crystalline silica SBA-15 ensured better metal dispersion. These reports prompted researchers to attempt to synthesize ITQ layered zeolites, silicalites having an organized structure like a "house of cards", characterized by a large surface area of about $600 \mathrm{~m}^{2} \cdot \mathrm{g}^{-1}$ and high thermal and hydrothermal stability, which distinguishes them from other mesoporous sieves. These systems were characterized by greater selectivity for $\mathrm{C}_{5+}$ hydrocarbons (to the order of $70 \%-80 \%$ ) than $\mathrm{Co} / \mathrm{SiO}_{2}$ or $\mathrm{Co} / \mathrm{MCM}-41$ systems (approximately $66 \%$ and $45 \%$ selectivity for $\mathrm{Co} / \mathrm{SiO}_{2}$ and $\mathrm{Co} / \mathrm{MCM}-41$, respectively). This is most likely due to the higher concentration of active sites, Co nanoparticles [4].

High activity (CO conversion around $77 \%$ ) and selectivity to higher hydrocarbons (aliphatic hydrocarbons: $C_{5}-C_{9}-11.3 \%, C_{10}-C_{20}-38.2 \%$, n-paraffins $-35.6 \%$, isoparaffins $-2.1 \%$ and olefins $-0.5 \%$ ) were also observed in the case of a catalyst containing $6 \mathrm{wt} \%$ of Co in zeolite Y. Such a system was obtained by incorporating metallic cobalt clusters into NaY zeolite channels. The authors stated that the formation of small metallic cobalt particles inside the zeolite channels was the reason for such high activity of the catalyst discussed in the paper [7].

Many scientists studied ZSM zeolites, most often ZSM-5, but also ZSM-11, ZSM-12 and ZSM-34 as supports for preparation of Co-containing zeolite catalysts for the FTS process $[4,6,10]$. They are all high-silica and strongly acidic, but they differ in pore size which has a great impact on the acidity of the catalysts and thus also on the activity of the Co/ZSM zeolite systems. ZSM-12 has the largest channel sizes with 12-rings, and the average pore size in the range of 5.7-6.1 $\AA$. ZSM-5 and ZSM-11 
zeolites are 10-ring, and their average pore sizes are for ZSM-5: 5.3-5.6 and 5.1-5.5 $\AA$, respectively, and for ZSM-11: 5.3-5.4 $\AA$. ZSM-34 is a synthetic zeolite having a complex channel system, containing in the structure 8 rings with $3.6-4.9 \AA$ pore size and 12 rings with approximately $6.7 \AA$ pore size and also a three-dimensional pore system containing 8 rings with 3.6-5.1 $\AA$ pore sizes. All these zeolite systems showed high selectivity for higher hydrocarbons (approximately $80 \%$ ) and selectivity for $\mathrm{CH}_{4}$ of $20 \%$. However, the important differences in $\mathrm{CO}$ conversion were observed. Catalyst activity increased according to the following series: Co/ZSM-34 $\left(\mathrm{K}_{\mathrm{CO}}=45 \%\right)<\mathrm{Co} / \mathrm{ZSM}-5, \mathrm{Co} / \mathrm{ZSM}-11\left(\mathrm{~K}_{\mathrm{CO}}=60 \%\right)<$ $\mathrm{Co} / \mathrm{ZSM}-12\left(\mathrm{~K}_{\mathrm{CO}}=79 \%\right)$, proportionally to decreasing the concentration of acid centers in the systems $(\mathrm{Co} / \mathrm{ZSM}-34>\mathrm{Co} / \mathrm{ZSM}-5>\mathrm{Co} / \mathrm{ZSM}-11>\mathrm{Co} / \mathrm{ZSM}-12)$. The lack of noticeable changes in the selectivity of the studied catalysts for methane and higher hydrocarbons indicates that the increase in the activity of the catalysts can be caused by the increase in the degree of metal dispersion and the formation of small cobalt nanoparticles in larger zeolite channels. The authors have not observed the shape-selective catalysis for these materials. They explain this phenomenon by a significant growth of hydrocarbon chains which occurred on the cobalt nanoparticles on the zeolite surface, and then the initially formed hydrocarbons are transformed into lighter products containing less n-alkanes on available acid centers in zeolite [10].

Previous surveys have reported that BEA zeolites exhibit interesting properties related to the presence of acidic sites, which significantly affect the activity and selectivity in hydrogenation of $\mathrm{CO}$ [11]. It is worthy to mention that the structure of BEA zeolite is not well defined. Since zeolite BEA has significant amounts of defects in the crystal lattice and thus shows a subtle structural disorder, it seems easy to modify its physico-chemical properties. It is believed that this disorder of the BEA zeolite structure is the cause of the formation of additional Lewis acidic sites, mostly located inside the zeolite. In contrast, Brønsted acid centers are related to tetrahedrally coordinated aluminum atoms present in the zeolite network both inside and on its outer surface. This internal exchange between Brønsted and Lewis acid centers localized on aluminum atoms in the network is characteristic of the BEA zeolite and distinguishes it from other aluminosilicate materials. It is associated with many structural defects that arise as a result of joining subsequent layers in position (001), where they form left or clockwise [12-14]. The nature of Brønsted and Lewis acid centers and the combination of Brønsted-Lewis acid sites, as well as their location (in pores or on the out of surface of crystallites) is still debatable [15]. Due to the presence of so many structural defects in the BEA zeolite network, its dealumination is possible and easy without destroying its crystal structure. It is also possible to reintroduce $\mathrm{Al}$ ions into the network, referred to as "realumination" [16-18]. Not only the Si/Al ratio can be modified through the dealumination process in zeolite BEA, but also its acidity, and this process could also affect its stability. The zeolite dealumination leads to the creation of a second, new zeolite channel and pore system that gives it new sorption and ion exchange properties [13].

Furthermore, the modification of zeolites by dealumination is a well-known method of enhancing their catalytic performance. The two-step postsynthesis preparation procedure consist of formation of vacant $\mathrm{T}$ - sites with associated silanol groups which then react with metal ions leading to creation of framework metal species with well-defined structure of zeolite $[19,20]$. The application of dealuminated zeolites as supports of cobalt have a strong effect on Co-support interaction, Co particles size and catalytic stability [1].

The physico-chemical properties of BEA zeolite significantly affect its catalytic properties and make it an especially useful catalyst in the petrochemical and refinery industries [14,21]. As this material is characterized by high hydrostability, acidity and hydrophobicity, Beta zeolite is a good catalyst in hydrocarbon cracking reactions, showing high selectivity towards the formation of gasoline and diesel fuels [21].

In this work the novel BEA zeolite catalysts prepared by two-step post-synthesis preparation procedure and conventional wet impregnation were used as catalysts for Fischer-Tropsch synthesis. The main aim was investigation of the role of the dispersion and the size of Co nanoparticles formed in BEA structure on the efficiency of FTS process and their impact on type of liquid products 
formation. The second important goal of this work was to investigate the correlation between reduction temperature, nanoparticles size and activity of supported Co-zeolite catalysts in FTS.

Another purpose of this study was exploring the differences in physicochemical properties of Red-C-Co ${ }_{5.0} \mathrm{HAlBEA}$ and Red-C-C $\mathrm{C}_{5.0} \mathrm{SiBEA}$ catalysts prepared by conventional wet impregnation and two-step postsynthesis preparation procedure, respectively. The presented studies confirmed the significant impact of the dealumination process on catalytic activity of the obtained Red-C-C ${ }_{5.0} \mathrm{SiBEA}$ catalyst. Total removal of $\mathrm{Al}$ atoms from $\mathrm{BEA}$ zeolites was proved by reduction of $\mathrm{Al}^{+}$ion signal on TOF-SIMS spectra and disappearance of both Lewis (L) and Brønsted (B) acidic sites.

The dealumination of zeolites had a strong impact on reducibility cobalt BEA catalyst. The presented data documented the influence of reduction temperature in the range of $500-900{ }^{\circ} \mathrm{C}$ on Co nanoparticles size, activity, and selectivity in FTS.

\section{Results and Discussion}

\subsection{The Textural Properties of $\mathrm{C}-\mathrm{Co}_{5.0} \mathrm{SiBEA}$ and $\mathrm{C}-\mathrm{Co}_{5.0} \mathrm{AlBEA}$ Samples}

The BET results obtained for $\mathrm{C}-\mathrm{CO}_{5.0} \mathrm{SiBEA}$ and $\mathrm{C}-\mathrm{CO}_{5.0}$ AlBEA calcined in static air at $500{ }^{\circ} \mathrm{C}$ for $3 \mathrm{~h}$ are presented in Table 1 . The specific surface area (SSA) of SiBEA zeolite $\left(600 \mathrm{~m}^{2} \mathrm{~g}^{-1}\right)$ is a slightly higher than SSA of C-C ${ }_{5.0}$ AlBEA $\left(535 \mathrm{~m}^{2} \mathrm{~g}^{-1}\right)$ and C-Co ${ }_{5.0} \operatorname{SiBEA}\left(496 \mathrm{~m}^{2} \mathrm{~g}^{-1}\right)$. It is related to the preparation methods used for introduction of cobalt ions in BEA zeolite. The slight drop of SSA for C-C ${ }_{5.0} \mathrm{SiBEA}$ and $\mathrm{C}-\mathrm{CO}_{5.0}$ AlBEA can be caused by blocking of part of pores and channels of BEA zeolites by formed cobalt oxides. The pore volume (PV) of calcined $\mathrm{C}-\mathrm{CO}_{5.0} \mathrm{SiBEA}$ and $\mathrm{C}-\mathrm{Co}_{5.0} \mathrm{AlBEA}$ zeolites is like that noticed for BEA zeolite, respectively, $0.21 \mathrm{~cm}^{3} \mathrm{~g}^{-1}$ and $0.22 \mathrm{~cm}^{3} \mathrm{~g}^{-1}$.

Table 1. The specific surface area (SSA) and pore volume (PV) of HAlBEA, C-Co ${ }_{5.0}$ AlBEA, SiBEA and C-Co5.0 $\mathrm{SiBEA}$.

\begin{tabular}{ccc}
\hline Sample & $\begin{array}{c}\text { SSA } \\
\left(\mathbf{m}^{\mathbf{2}} \mathbf{g}^{-\mathbf{1}}\right)\end{array}$ & $\begin{array}{c}\mathbf{P V} \\
\left(\mathbf{c m}^{\mathbf{3}} \mathbf{g}^{-\mathbf{1}} \mathbf{)}\right.\end{array}$ \\
\hline HAlBEA & 610 & 0.22 \\
C-Co ${ }_{5.0}$ AlBEA & 535 & 0.22 \\
SiBEA & 600 & 0.21 \\
C-Co . $_{.0}$ SiBEA & 496 & 0.21 \\
\hline
\end{tabular}

\subsection{Prove of Co Incorporation in the HAlBEA and SiBEA Zeolite Structure}

It is well known [22] that a diffraction peak close to $22-23^{\circ}$ could be applied to determine the contraction/expansion of the structure of BEA zeolite. The $d_{302}$ spacing corresponding to the peak with $2 \theta$ of $22.57^{\circ}$ (AlBEA) decreases with dealumination and the peak with $2 \theta$ of $22.61^{\circ}$ (SiBEA) appears (Figure 1). This prove some contraction of the zeolite BEA matrix because of dealumination. After introduction of cobalt into HAlBEA and SiBEA, the narrow diffraction peak appears at lower $2 \theta$ of $22.46^{\circ}$ for $\mathrm{C}^{-} \mathrm{Co}_{5.0} \mathrm{AlBEA}$ and of $22.56^{\circ}$ for $\mathrm{C}-\mathrm{Co}_{5.0} \mathrm{SiBEA}$. This indicates expansion of the zeolite BEA structure and proves that part of Co ions is incorporated in the framework of BEA zeolite as tetrahedral $\mathrm{Co}(\mathrm{II})$ species, in line with earlier report $[23,24]$. The much smaller diffraction peak occurred at around 22.46-22.56 ${ }^{\circ}$ for $\mathrm{C}-\mathrm{CO}_{5.0}$ AlBEA and $\mathrm{C}-\mathrm{Co}_{5.0} \mathrm{SiBEA}$ than for HAlBEA and SiBEA is probably related with formation of $\mathrm{Co}_{3} \mathrm{O}_{4}$ in extra-framework position of these zeolites, as confirmed by the diffraction line at $2 \theta=36.7^{\circ}$ characteristic of $\mathrm{Co}_{3} \mathrm{O}_{4}$. It is worth to mention that the absence of more than one diffraction lines characteristic for cobalt oxides could be related to good dispersion of Co(II) species in both zeolites or may be assigned to small nanoparticles size of cobalt oxides, what can cause the limit of their detection [20]. 


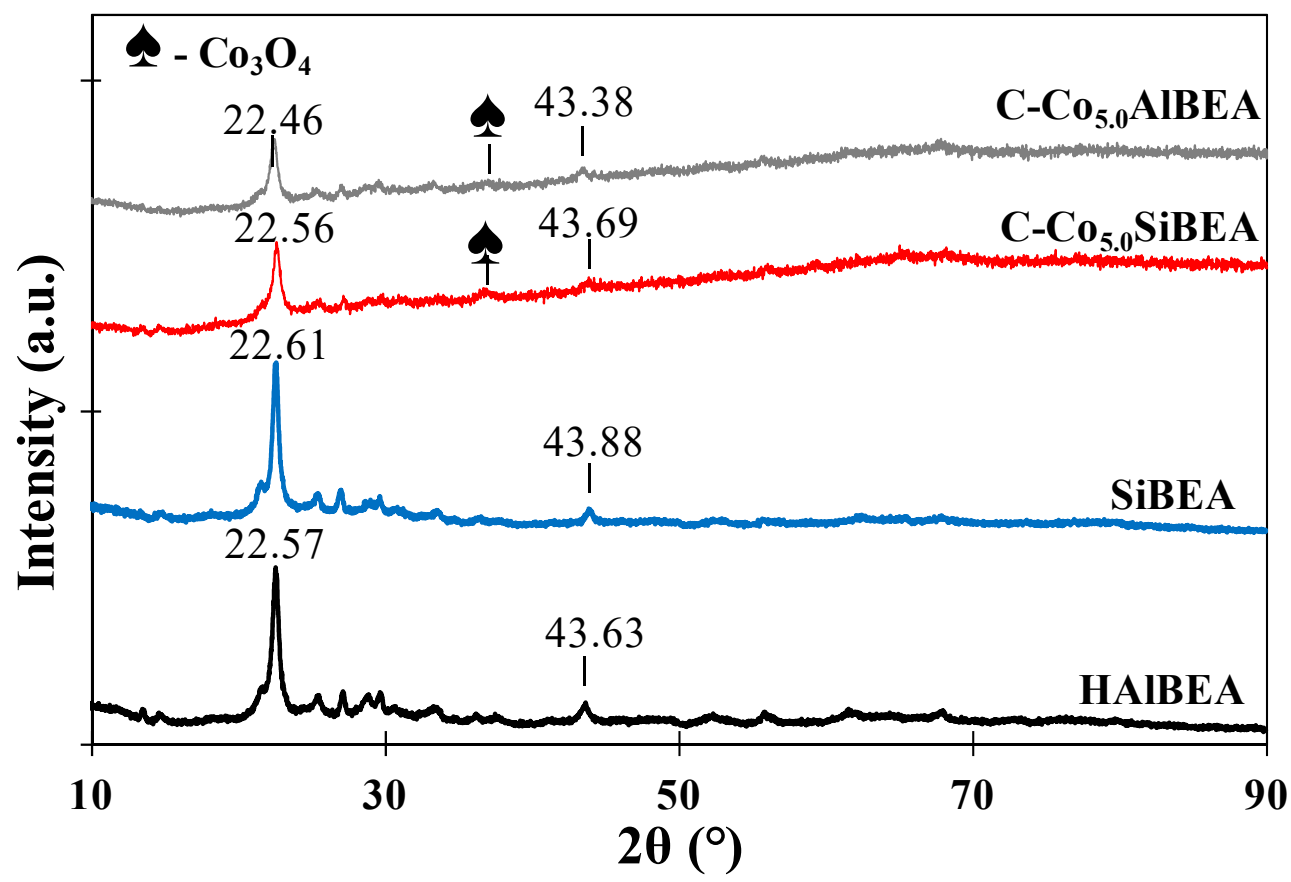

Figure 1. XRD diffractograms of HAlBEA, SiBEA, C-CO ${ }_{5.0} \mathrm{AlBEA}$ and $\mathrm{C}-\mathrm{CO}_{5.0} \mathrm{SiBEA}$ showing contraction of the zeolite matrix after dealumination and expansion after incorporation of Co cations.

\subsection{The Reducibility of Co Present in $\mathrm{C}-\mathrm{Co}_{5.0} \mathrm{SiBEA}$ and $\mathrm{C}-\mathrm{Co}_{5.0} \mathrm{AlBEA}$}

The TPR- $\mathrm{H}_{2}$ curves of $\mathrm{C}-\mathrm{CO}_{5.0} \mathrm{AlBEA}$ and $\mathrm{C}-\mathrm{CO}_{5.0} \mathrm{SiBEA}$ presented in Figure 2, show a multistage process of reduction of cobalt for both samples.

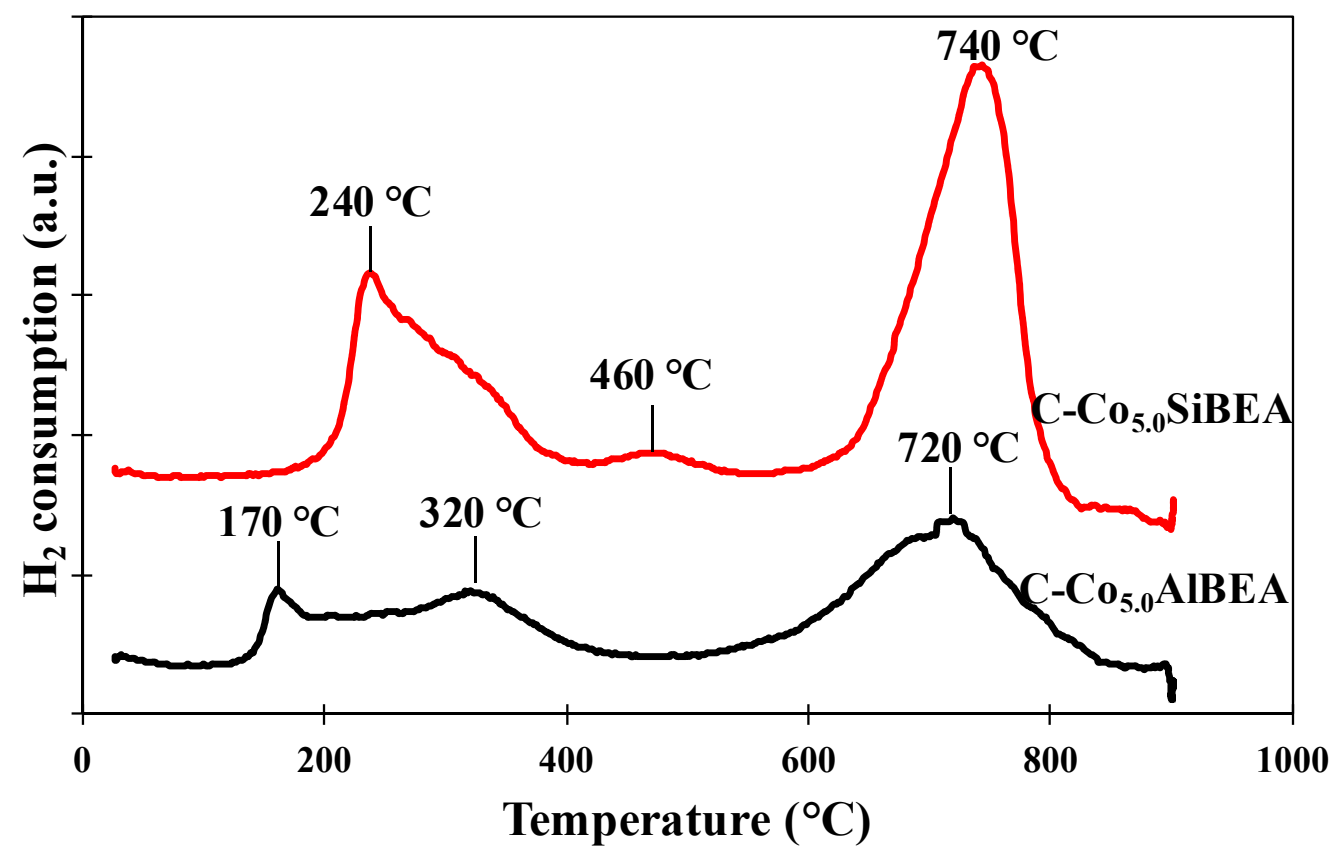

Figure 2. TPR- $\mathrm{H}_{2}$ profiles of $\mathrm{C}-\mathrm{Co}_{5.0} \mathrm{AlBEA}$ and $\mathrm{C}-\mathrm{Co}_{5.0} \mathrm{SiBEA}$ performed in the temperature between 25 and $900{ }^{\circ} \mathrm{C}$ showing that $\mathrm{C}-\mathrm{Co}_{5.0} \mathrm{SiBEA}$ is hardly reduced than $\mathrm{C}-\mathrm{Co}_{5.0} \mathrm{AlBEA}$.

The TPR profile of $\mathrm{C}-\mathrm{CO}_{5.0} \mathrm{AlBEA}$ (Figure 2) shows three reduction peaks. Two of them with a maximum at 170 and $320^{\circ} \mathrm{C}$ can be related to two-stage reduction of $\mathrm{Co}_{3} \mathrm{O}_{4}$ to metallic cobalt $\mathrm{Co}(0)$ $\left(\mathrm{Co}_{3} \mathrm{O}_{4} \rightarrow \mathrm{CoO} \rightarrow \mathrm{Co}(0)\right)$ whereas the third peak at a much higher temperature $\left(720^{\circ} \mathrm{C}\right)$ is probably 
related to the reduction of $\mathrm{Co}(\mathrm{II})$ species present in ion exchange position and/or to reduction of cobalt alumina-silicate. The similar results were obtained by Xiao for $5 \% \mathrm{Co} / \mathrm{H}-\mathrm{ZSM}-5$ system [25].

The reduction profile of $\mathrm{C}-\mathrm{CO}_{5.0} \mathrm{SiBEA}$ catalyst presents one peak at $240{ }^{\circ} \mathrm{C}$ with shoulder at about $320^{\circ} \mathrm{C}$ (Figure 2). They are attributed to reduction of $\mathrm{Co}_{3} \mathrm{O}_{4}$ to metallic $\mathrm{Co}(0)$. Third reduction peak at $460^{\circ} \mathrm{C}$ could be assigned to reduction of cobalt present as surface silicates $\left(\mathrm{Co}_{2} \mathrm{SiO}_{4}\right)$, that presence was proved by ToF-SIMS results. The fourth reduction peak at $740{ }^{\circ} \mathrm{C}$ for $\mathrm{C}-\mathrm{CO}_{5.0} \mathrm{SiBEA}$ probably corresponds to reduction of framework tetrahedral $\mathrm{Co}(\mathrm{II})$, in agreement with our previous report [1].

Comparison of the reduction profile of $\mathrm{C}-\mathrm{CO}_{5.0} \mathrm{SiBEA}$ and $\mathrm{C}-\mathrm{Co}_{5.0} \mathrm{AlBEA}$ in Figure 2 allow to suggest that $\mathrm{C}-\mathrm{CO}_{5.0} \mathrm{SiBEA}$ is hardly reduced than $\mathrm{C}-\mathrm{CO}_{5.0} \mathrm{AlBEA}$. It could correspond to the presence of a larger amount of $\mathrm{Co}$ atoms in the framework position of $\mathrm{C}-\mathrm{CO}_{5.0} \mathrm{SiBEA}$ than in $\mathrm{C}-\mathrm{CO}_{5.0} \mathrm{AlBEA}$. The $\mathrm{Co}$ present in the framework of the BEA zeolite is much more strongly interacted with the zeolite structure than that present in the extra-framework position, and this is the reason for the harder reducibility of this Co species.

To get a better insight into the nature of cobalt present in $\mathrm{C}-\mathrm{CO}_{5.0} \mathrm{SiBEA}$ and $\mathrm{C}-\mathrm{CO}_{5.0} \mathrm{AlBEA}$, a time-of-flight secondary ion mass spectrometry (ToF-SIMS) analysis was performed. The results are presented in Table 2 and Figures 3 and 4.

Table 2. The normalized intensities of secondary ions calculated using ToF-SIMS data obtained for C-Co ${ }_{5.0} \mathrm{AlBEA}$ and $\mathrm{C}-\mathrm{CO}_{5.0} \mathrm{SiBEA}$.

\begin{tabular}{ccc}
\hline Sample & C-Co $_{5.0}$ AlBEA & C-Co $_{5.0}$ SiBEA \\
\hline Ions: & $\begin{array}{c}\text { The Normalized } \\
\text { Ions Intensities }\end{array}$ & \\
$\mathrm{Al}^{+} /$total Ion & $3.3 \times 10^{-2}$ & $1.9 \times 10^{-3}$ \\
$\mathrm{Si}^{+} /$total Ion & 0.11 & 0.2 \\
$\mathrm{Al}^{+} / \mathrm{Si}^{+}$ & 0.32 & $9.7 \times 10^{-3}$ \\
$\mathrm{SiOAl}^{+} /$total Ion & $4.7 \times 10^{-4}$ & - \\
$\mathrm{CoAlO}_{2} \mathrm{H}^{+} /$total Ion & $2.7 \times 10^{-4}$ & - \\
$\mathrm{CoAl}_{2} \mathrm{O}_{4} \mathrm{H}^{+} /$total Ion & $1.1 \times 10^{-4}$ & - \\
$\mathrm{CoSiO}^{+} /$total Ion & $1.7 \times 10^{-3}$ & $9.0 \times 10^{-4}$ \\
$\mathrm{CoSiOH}^{+} /$total Ion & $3.3 \times 10^{-4}$ & $1.7 \times 10^{-4}$ \\
$\mathrm{CoSiO}_{2} \mathrm{H}^{+} /$total Ion & $7.8 \times 10^{-4}$ & $3.9 \times 10^{-4}$ \\
\hline
\end{tabular}

An analysis of ToF-SIMS spectra obtained for C-C ${ }_{5.0} \mathrm{AlBEA}$ shows the presence of $\mathrm{SiOAl}^{+}$, $\mathrm{CoAlO}_{2} \mathrm{H}^{+}$and $\mathrm{CoAl}_{2} \mathrm{O}_{4} \mathrm{H}^{+}$ions indicating the formation of aluminates and aluminosilicates of cobalt. In the case of $\mathrm{C}-\mathrm{Co}_{5.0} \mathrm{SiBEA}$ the signals attributed to $\mathrm{CoAlO}_{2} \mathrm{H}^{+}$and $\mathrm{CoAl}_{2} \mathrm{O}_{4} \mathrm{H}^{+}$were not observed. Further analysis demonstrates also a much lower intensity of $\mathrm{Al}^{+}$signal in the case of $\mathrm{C}-\mathrm{Co}_{5.0} \mathrm{SiBEA}$

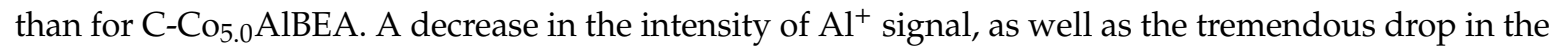
intensity ratio $\mathrm{Al}^{+} / \mathrm{Si}^{+}$(Table 2 and Figure 3) clearly confirmed that dealumination process occurring in the first step of preparation of $\mathrm{C}-\mathrm{CO}_{5.0} \mathrm{SiBEA}$ was successful.

Secondary ion mass spectra of the analyzed catalysts exhibit the presence of signals originating from $\mathrm{CoSiO}^{+}, \mathrm{CoSiOH}^{+}$and $\mathrm{CoSiO}_{2} \mathrm{H}^{+}$ions. It confirms the presence of Co-silicates in the case of both $\mathrm{C}-\mathrm{CO}_{5.0} \mathrm{SiBEA}$ and $\mathrm{C}-\mathrm{Co}_{5.0} \mathrm{AlBEA}$ materials and the incorporation of $\mathrm{Co}$ into the zeolite framework (Table 2 and Figure 4). 

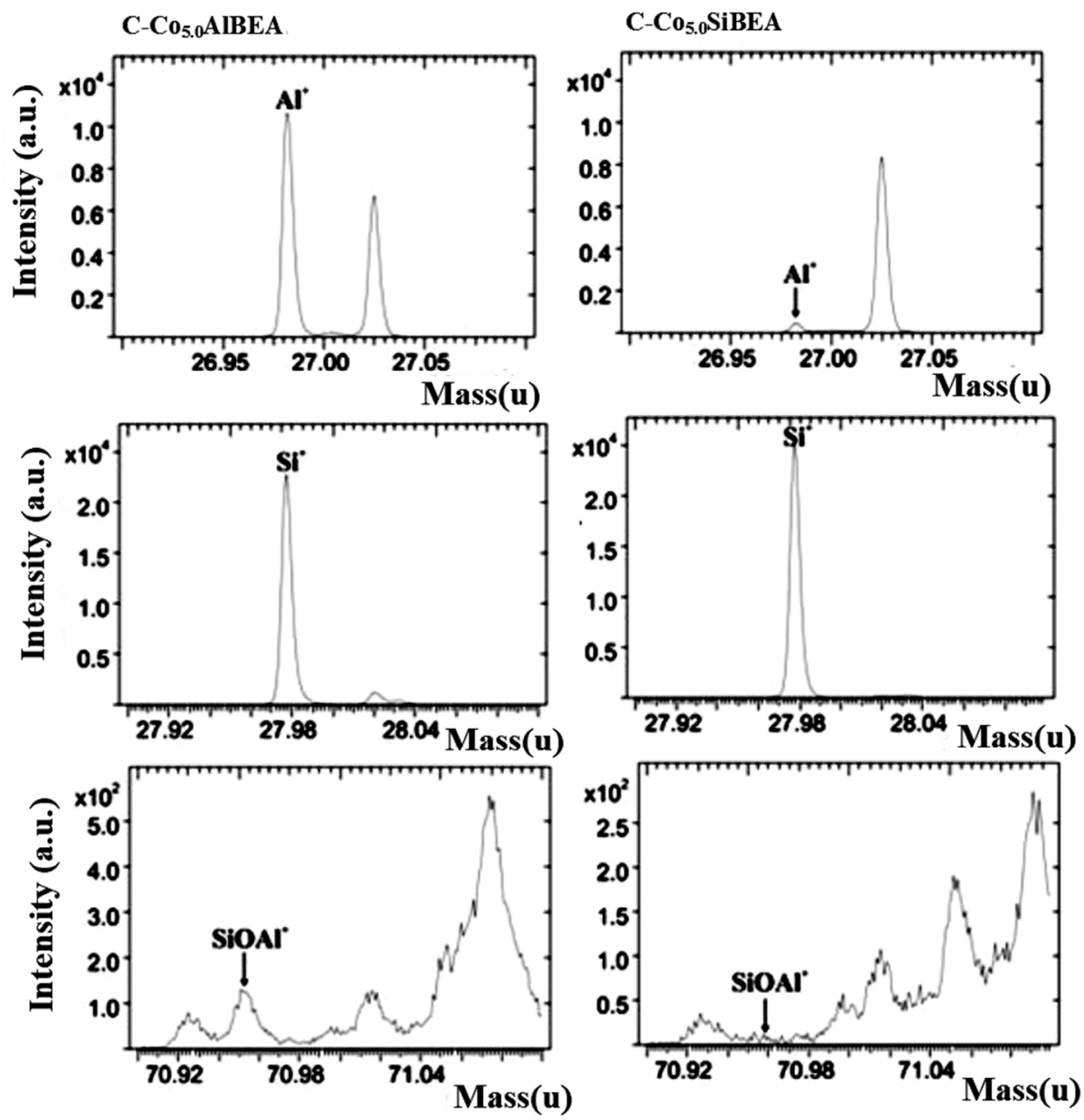

Figure 3. ToF-SIMS spectra of $\mathrm{Al}^{+}, \mathrm{Si}^{+}$and $\mathrm{SiOAl}^{+}$ions collected for $\mathrm{C}-\mathrm{Co}_{5.0} \mathrm{AlBEA}$ and $\mathrm{C}-\mathrm{Co}_{5.0} \mathrm{SiBEA}$.
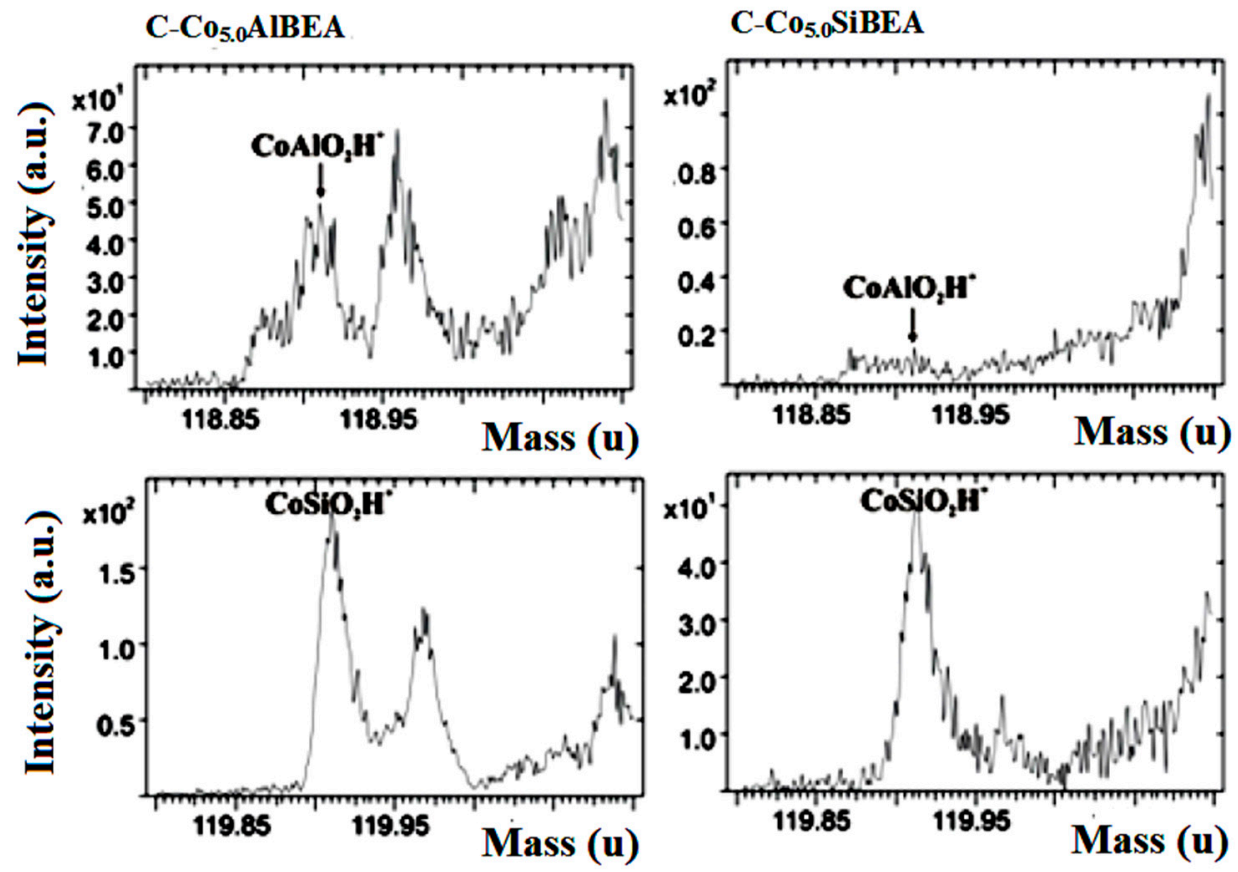

Figure 4. ToF-SIMS spectra of $\mathrm{CoAlO}_{2} \mathrm{H}^{+}$and $\mathrm{CoSiO}_{2} \mathrm{H}^{+}$ions collected for C-Co5.0 AlBEA and C-Co ${ }_{5.0} \mathrm{SiBEA}$. 


\subsection{The Cobalt Nanoparticles Distribution in Red-C-Co $0_{5.0} S i B E A$ after Reduction in Different Conditions}

The cobalt nanoparticles distributions in Red-C-C ${ }_{5.0}$ SiBEA reduced at 800 and $900{ }^{\circ} \mathrm{C}$ in $100 \% \mathrm{H}_{2}$ and $5 \% \mathrm{H}_{2}-95 \%$ Ar mixture were investigated by TEM and results of studies are presented in Figure 5 .
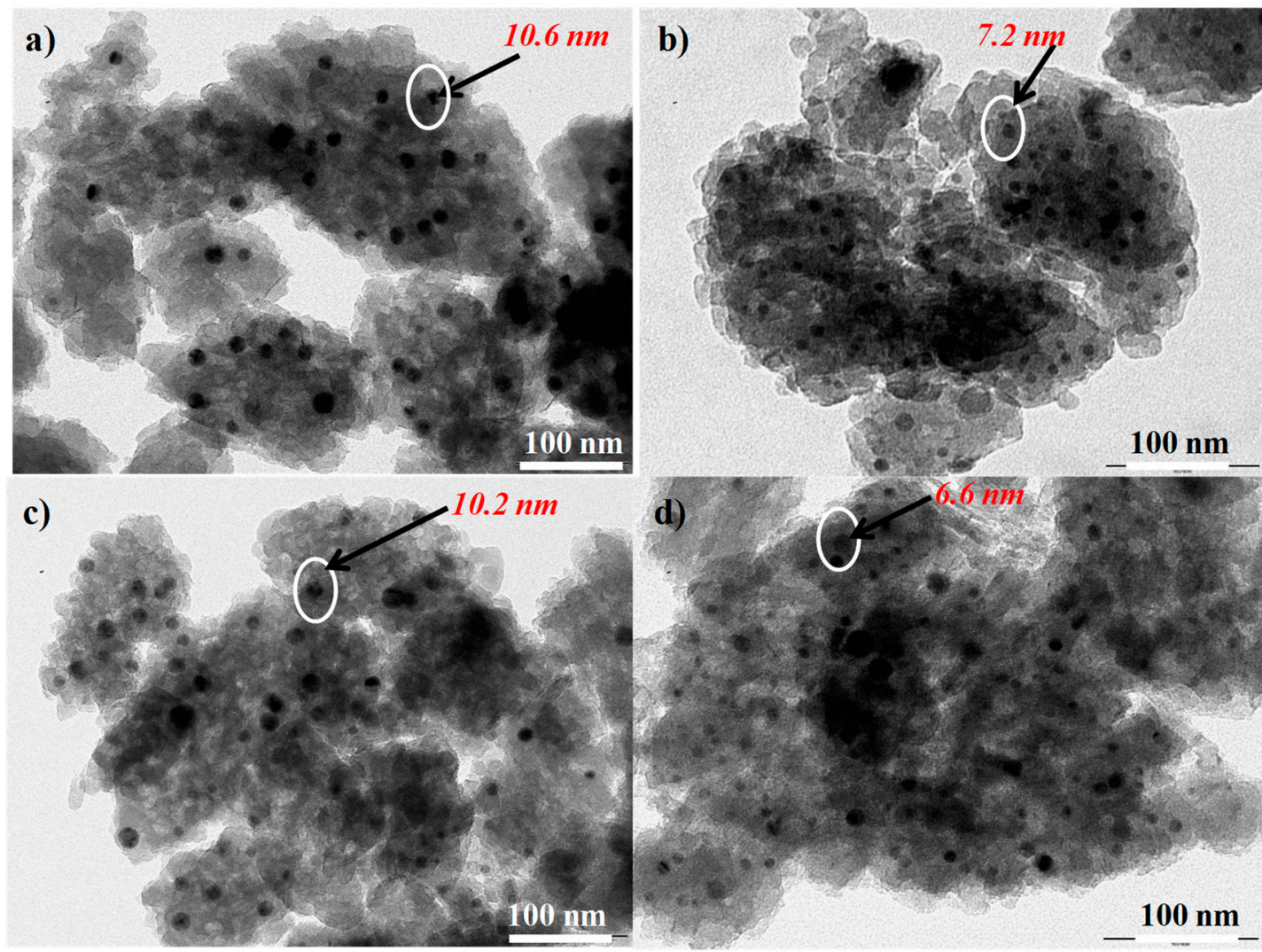

Figure 5. TEM EDS images of Red-C- $\mathrm{Co}_{5.0} \mathrm{SiBEA}$ reduced at $800{ }^{\circ} \mathrm{C}$ in $5 \% \mathrm{H}_{2}-95 \%$ Ar flow (a), $100 \% \mathrm{H}_{2}$ flow (b), $900{ }^{\circ} \mathrm{C}$ in $5 \% \mathrm{H}_{2}-95 \%$ Ar flow (c), $100 \% \mathrm{H}_{2}$ flow (d) showing that the size of cobalt nanoparticles does not change after reduction in higher temperature.

The average nanoparticles size of cobalt in Red-C- $\mathrm{Co}_{5.0} \mathrm{SiBEA}$ catalyst reduced at $800{ }^{\circ} \mathrm{C}$ in $5 \%$ $\mathrm{H}_{2}-95 \%$ Ar mixture (Figure $5 \mathrm{a}$ ) and $100 \% \mathrm{H}_{2}$ (Figure $5 \mathrm{~b}$ ) is 10.6 and $7.2 \mathrm{~nm}$, respectively. The increase of reduction temperature up to $900{ }^{\circ} \mathrm{C}$ has no influence on size of Co nanoparticles, which is 10.2 and $6.6 \mathrm{~nm}$ respectively (Figure $5 \mathrm{c}, \mathrm{d}$ ). It indicates that reduction in pure hydrogen leads to formation of cobalt nanoparticles with smaller size than reduction in $5 \% \mathrm{H}_{2}-95 \%$ Ar mixture. It may indicate that cobalt nanoparticles are well dispersed in zeolite matrix and cobalt nanoparticles size do not change with increasing of reduction temperature from 800 to $900{ }^{\circ} \mathrm{C}$. It means that the temperature of the reduction is not so important but that the key factor affecting Co size in the studied catalysts is the reducing medium. It seems that, for the reduction and obtaining of smaller cobalt nanoparticles size, the use of pure hydrogen is more proper, and it shows that the size of cobalt nanoparticles in Red-C- $\mathrm{Co}_{5.0} \mathrm{SiBEA}$ does not change after reduction in higher temperature (Figure 5).

\subsection{The Acidity of $\mathrm{C}-\mathrm{Co}_{x} \mathrm{SiBEA}$ and $\mathrm{C}-\mathrm{Co}_{x} \mathrm{AlBEA}$}

The patterns of TPD-NH 3 for C-CO ${ }_{5.0}$ AlBEA, C-C ${ }_{5.0} \mathrm{SiBEA}, \mathrm{Red}-\mathrm{C}-\mathrm{C}_{5.0} \mathrm{AlBEA}$ and Red-C-CO ${ }_{5.0} \mathrm{SiBEA}$ are shown in Figure $6 \mathrm{a}, \mathrm{b}$. In the patterns of $\mathrm{C}-\mathrm{CO}_{5.0} \mathrm{AlBEA}$ and $\mathrm{C}-\mathrm{CO}_{5.0} \mathrm{SiBEA}$ only one large desorption peak at $200-220^{\circ} \mathrm{C}$ is present corresponding to weak acidic sites [1]. 

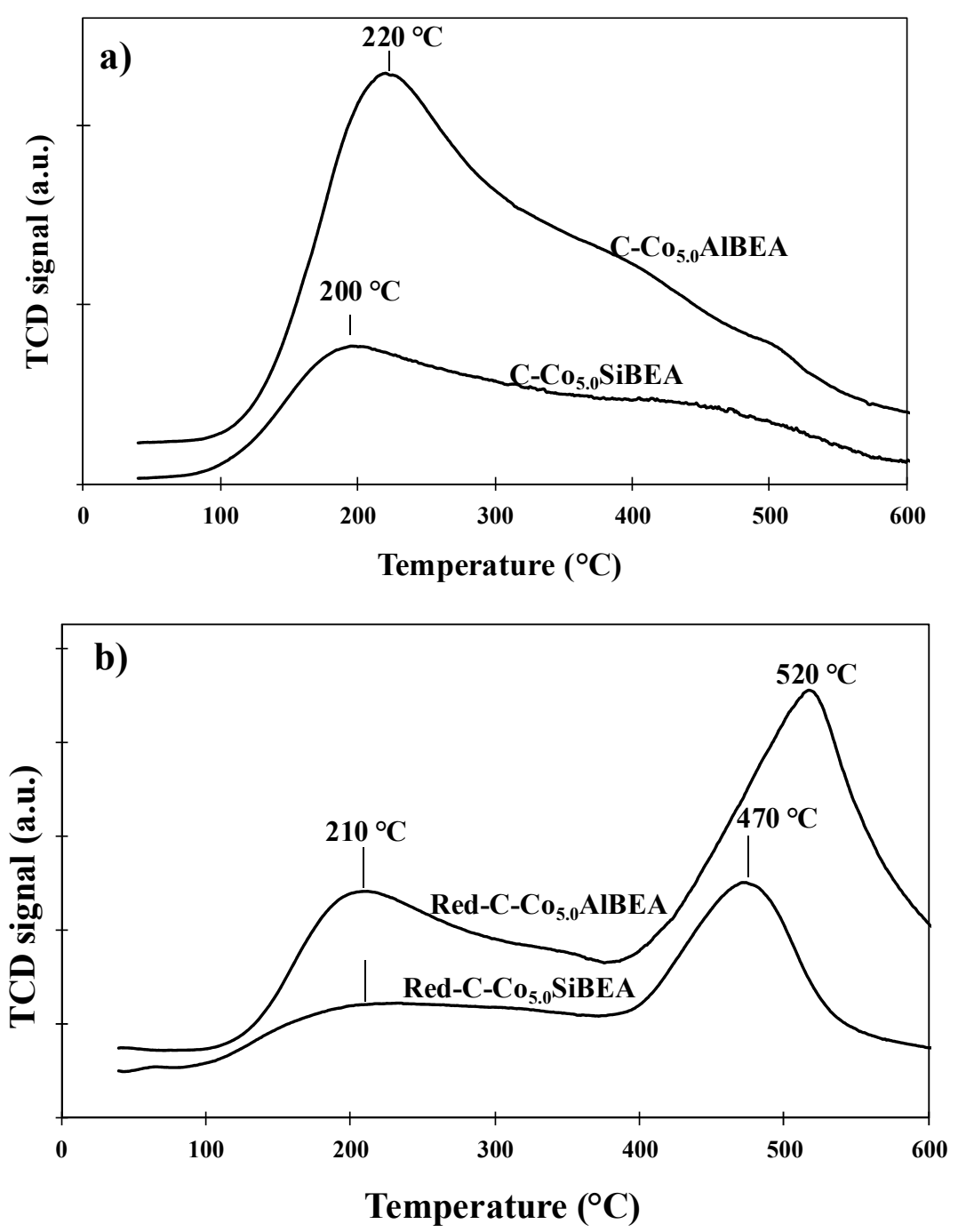

Figure 6. TPD-NH 3 patterns for $\mathrm{C}-\mathrm{CO}_{5.0} \mathrm{AlBEA}$ and $\mathrm{C}-\mathrm{CO}_{5.0} \mathrm{SiBEA}$ (a) and Red-C-Co ${ }_{5.0} \mathrm{AlBEA}$ and Red-C-C ${ }_{5.0}$ SiBEA reduced in $\mathrm{H}_{2}$ at $500{ }^{\circ} \mathrm{C}$ for $1 \mathrm{~h} \mathrm{(b)}$.

Red-C-Co ${ }_{5.0}$ AlBEA and Red-C-Co ${ }_{5.0} \mathrm{SiBEA}$ catalysts after reduction in $100 \% \mathrm{H}_{2}$ at $500{ }^{\circ} \mathrm{C}$ for $1 \mathrm{~h}$ show the TPD-NH 3 patterns, that could be fitted by two peaks at 210 and $520^{\circ} \mathrm{C}$ for Red-C-Co ${ }_{5.0}$ AlBEA and at 210 and $470{ }^{\circ} \mathrm{C}$ for Red-C-Co ${ }_{5.0} \mathrm{SiBEA}$. These peaks could be attributed to desorption of $\mathrm{NH}_{3}$ from weak and strong acidic sites, respectively [1,26,27].

The $\mathrm{NH}_{3}$ desorption temperature and amount of desorbed ammonia allow to determine total acidity of catalysts. C-C ${ }_{5.0}$ AlBEA and $\mathrm{C}-\mathrm{CO}_{5.0} \mathrm{SiBEA}$ demonstrate higher acidity than Red-C-C ${ }_{5.0}$ AlBEA and Red-C-C ${ }_{5.0}$ SiBEA, respectively (Table 3). Indeed, the amount of ammonia decreases significantly after reduction in hydrogen from $3000 \mu \mathrm{mol} \cdot \mathrm{g}^{-1}$ for C-Co ${ }_{5.0} \mathrm{AlBEA}$ to $32 \mu \mathrm{mol} \cdot \mathrm{g}^{-1}$ for Red-C-Co ${ }_{5.0}$ AlBEA and from $1740 \mu \mathrm{mol} \cdot \mathrm{g}^{-1}$ for C-CO ${ }_{5.0}$ SiBEA to $13 \mu \mathrm{mol} \mathrm{g}^{-1}$ for Red-C-CO ${ }_{5.0} \mathrm{SiBEA}$. These results allow to prove the creation of metallic $\mathrm{Co}(0)$ during reduction [1].

Table 3. The acidity of $\mathrm{C}-\mathrm{Co}_{5.0} \mathrm{AlBEA}$ and $\mathrm{C}-\mathrm{Co}_{5.0} \mathrm{SiBEA}$ calculated from $\mathrm{TPD}-\mathrm{NH}_{3}$ data.

\begin{tabular}{cc}
\hline Sample & Amount of $\mathbf{N H}_{\mathbf{3}}$ Adsorbed $\left(\mu \mathbf{m o l} \mathbf{~ g}^{\mathbf{- 1}}\right)$ \\
\hline C-Co ${ }_{5.0}$ AlBEA & 3000 \\
Red-C-Co 5.0 AlBEA & 32 \\
C-Co ${ }_{5.0}$ SiBEA & 1740 \\
Red-C-Co5.0 $\mathrm{SiBEA}$ & 13 \\
\hline
\end{tabular}


In order to check acidity of HAlBEA, SiBEA, C-Co ${ }_{5.0}$ AlBEA and C-CO ${ }_{5.0}$ SiBEA FTIR spectra of pyridine adsorbed on these materials were analyzed (Table 4, Figure 7). One can observe the high amount of $B$ and $L$ acidic sites on HAlBEA. The incorporation of cobalt into HAlBEA leads to formation of $\mathrm{Co}_{5.0} \mathrm{AlBEA}$ with higher amount of acidic sites than for HAlBEA, as shown by appearance of very intense bands at 1451 and $1611 \mathrm{~cm}^{-1}$ and with lower amount of $B$ acidic sites shown by lower intensity of the bands at 1546 and $1637 \mathrm{~cm}^{-1}$ (Table 4 and Figure 7).

Table 4. Evolution of the B and $\mathrm{L}$ acidic sites concentration in $\mathrm{C}-\mathrm{CO}_{5.0} \mathrm{HAlBEA}, \mathrm{HAlBEA}, \mathrm{C}-\mathrm{Co}_{5.0} \mathrm{SiBEA}$ and SiBEA.

\begin{tabular}{|c|c|c|}
\hline Sample & $\begin{array}{l}\text { B Acidic Sites } \\
\left(\mu \mathrm{mol} \mathrm{g}^{-1}\right)^{a}\end{array}$ & $\begin{array}{l}\text { L Acidic Sites } \\
\left(\mu \mathrm{mol} \mathrm{g}^{-1}\right)\end{array}$ \\
\hline HAlBEA & 353 & 158 \\
\hline C-Co ${ }_{5.0} \mathrm{HAlBEA}$ & 85 & 439 \\
\hline SiBEA & 0 & 0 \\
\hline C-Co ${ }_{5.0} \mathrm{SiBEA}$ & 0 & 259 \\
\hline
\end{tabular}

${ }^{a}$ The determination of number of acidic centers in zeolites was done by using absorption coefficient factor reported earlier by Emeis [28].

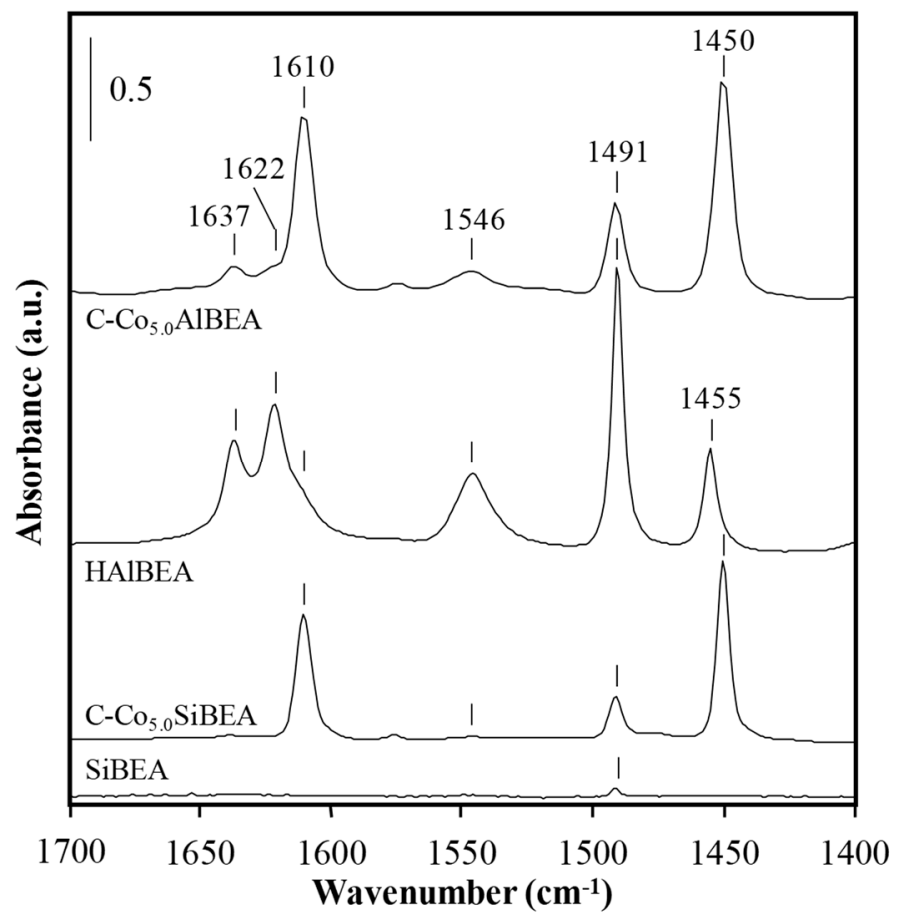

Figure 7. FTIR spectra of AlBEA, SiBEA, $\mathrm{CO}_{5.0} \mathrm{AlBEA}$ and $\mathrm{CO}_{5.0} \mathrm{SiBEA}$ after desorption of pyridine at $150{ }^{\circ} \mathrm{C}$ showing no Brønsted and Lewis acidic sites in siliceous SiBEA.

In SiBEA there is no B and L acidic sites (Table 4). It suggests that the Al removal from BEA zeolite under dealumination process is almost complete what, in consequence, leads to the disappearance of both $\mathrm{B}$ and $\mathrm{L}$ acidic sites. The introduction of cobalt into the siliceous SiBEA leads to formation of $\mathrm{L}$ acidic sites proved by the bands at 1451, 1492 and $1611 \mathrm{~cm}^{-1}$ [20].

\subsection{The Catalytic Activity of Red-C-Co ${ }_{5.0} A l B E A$ and Red-C-Co ${ }_{5.0}$ SiBEA}

The FTS was performed on Red-C-Co ${ }_{5.0} \mathrm{SiBEA}$ and Red-C-Co5.0AlBEA catalysts. The influence of the reduction temperature on the activity of these catalysts is presented in Table 5. Conversion of $\mathrm{CO}$ and selectivity to liquid products, $\mathrm{CH}_{4}$ and $\mathrm{CO}_{2}$ were analyzed. The Red-C-Co5.0 SiBEA catalyst appears to be the most active and most selective to liquid products (hydrocarbons $\mathrm{C}_{5+}$ ), obtained by 
two-step postsynthesis preparation procedure. The Red-C-Co 5.0 $_{0} \mathrm{SiBEA}$ catalyst, reduced at $500{ }^{\circ} \mathrm{C}$, is very selective in production of liquid hydrocarbons with $91 \%$ selectivity for the CO conversion of $11 \%$, whereas the Red-C- $\mathrm{CO}_{5.0}$ AlBEA reduced under the same conditions was not active in $\mathrm{CO}$ conversion. Moreover, it was observed that the higher reduction temperature $\left(800\right.$ and $\left.900^{\circ} \mathrm{C}\right)$, when all Co species in the Red-C-C ${ }_{5.0} \mathrm{SiBEA}$ sample are reduced to metallic cobalt, does not improve its activity. It was found that for the sample reduced at $800{ }^{\circ} \mathrm{C}$ in pure hydrogen $\left(100 \% \mathrm{H}_{2}\right)$ the conversion of $\mathrm{CO}$ and the selectivity to liquid products were much lower than for Red-C-C ${ }_{5.0}$ SiBEA reduced at $500{ }^{\circ} \mathrm{C}$, at $3 \%$ and $67 \%$, respectively. The selectivity towards methane was three times higher and it was $33 \%$. Further increasing of the reduction temperature (up to $900{ }^{\circ} \mathrm{C}$ ) causes also decline in activity and selectivity of Red-C-C 5. $_{50} \mathrm{SiBEA}$. However, in this case the impact of reduction mixture was noticed. It was observed that reduction at 800 and $900{ }^{\circ} \mathrm{C}$ in $5 \% \mathrm{H}_{2}-95 \%$ Ar mixture flow led to high selectivity towards liquid products ( 89 and $88 \%$ respectively) but CO conversion was more than two times lower than in the case Red-C-Co ${ }_{5.0} \mathrm{SiBEA}$ sample reduced at $500{ }^{\circ} \mathrm{C}$.

Table 5. The catalytic activity and selectivity, the isoalkanes and olefins to n-alkanes ratio and nanoparticles size for Red-C-CO ${ }_{5.0}$ AlBEA and Red-C-Co ${ }_{5.0}$ SiBEA.

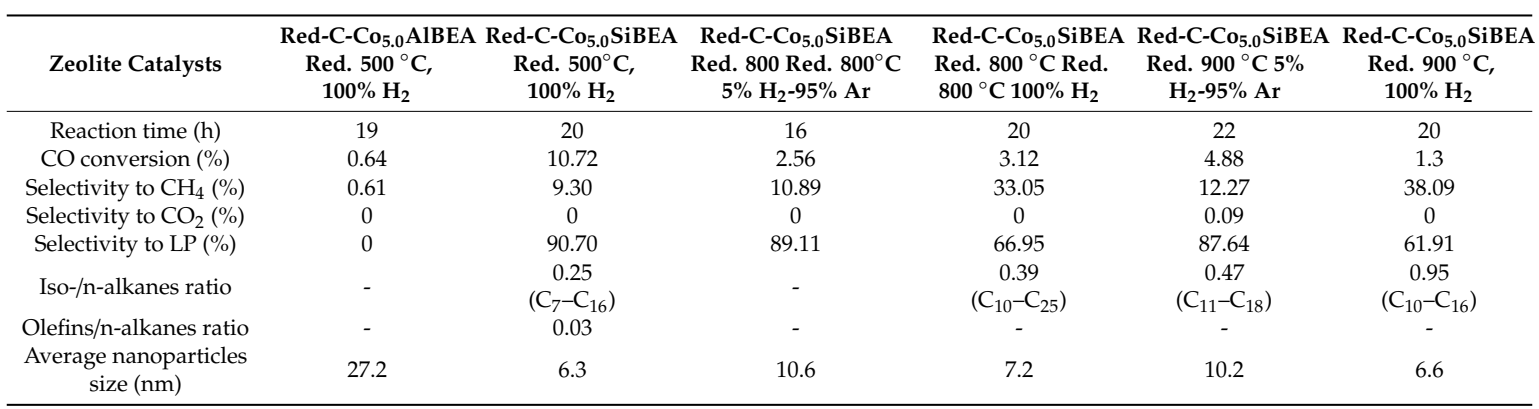

The higher activity of Red-C-C ${ }_{5.0} \mathrm{SiBEA}$ reduced at $500{ }^{\circ} \mathrm{C}$ than at 800 and $900{ }^{\circ} \mathrm{C}$ seems to be related to its smaller cobalt nanoparticles size. The average particles size for Red-C- $\mathrm{Co}_{5.0} \mathrm{SiBEA}$ reduced in $100 \% \mathrm{H}_{2}$ at 500,800 and $900{ }^{\circ} \mathrm{C}$ is $6.3,7.2$ and $6.6 \mathrm{~nm}$, respectively. The same catalyst reduced in $5 \% \mathrm{H}_{2}-95 \%$ Ar mixture at $800-900{ }^{\circ} \mathrm{C}$ shows slightly bigger Co nanoparticles (about $10-11 \mathrm{~nm}$ ). The obtained results proved that the important factor, which impacts cobalt nanoparticles size, is the dealumination process. The catalyst dealuminated and activated in various conditions (Red-C-Co ${ }_{5.0} \mathrm{SiBEA}$ ) show Co nanoparticles of about $6-10 \mathrm{~nm}$, whereas the catalyst prepared without dealumination (Red-C-C ${ }_{5.0}$ AlBEA) show large Co nanoparticles of about $27 \mathrm{~nm}$. This suggests that the optimal nanoparticles size of metallic cobalt in catalysts, which ensures high activity and selectivity towards liquid products in FTS, is 6-10 nm. The larger Co nanoparticles size is not required, since the dispersion of metallic cobalt will be lower and will cause lower hydrogen uptake [29]. The similar phenomenon was observed for Co/ITQ [4], Co/Y [7] and Co/ZSM-5; ZSM-11; ZSM-12; ZSM-34 zeolites [10].

The liquid products were analyzed by GC-MS technique and the results are shown in Figures 8-11. The quantitative analysis is presented in Table 5. It was found that the liquid fraction in FTS catalyzed by Co supported zeolites varies depending on the activation conditions of the catalyst. In the case of FTS carried out on the Red-C-C ${ }_{5.0} \mathrm{SiBEA}$ sample reduced at $500{ }^{\circ} \mathrm{C}$, both saturated (alkanes, isolkanes) and unsaturated (olefins) hydrocarbons $\left(C_{7}-C_{16}\right)$ were identified (Figure 8 ). 


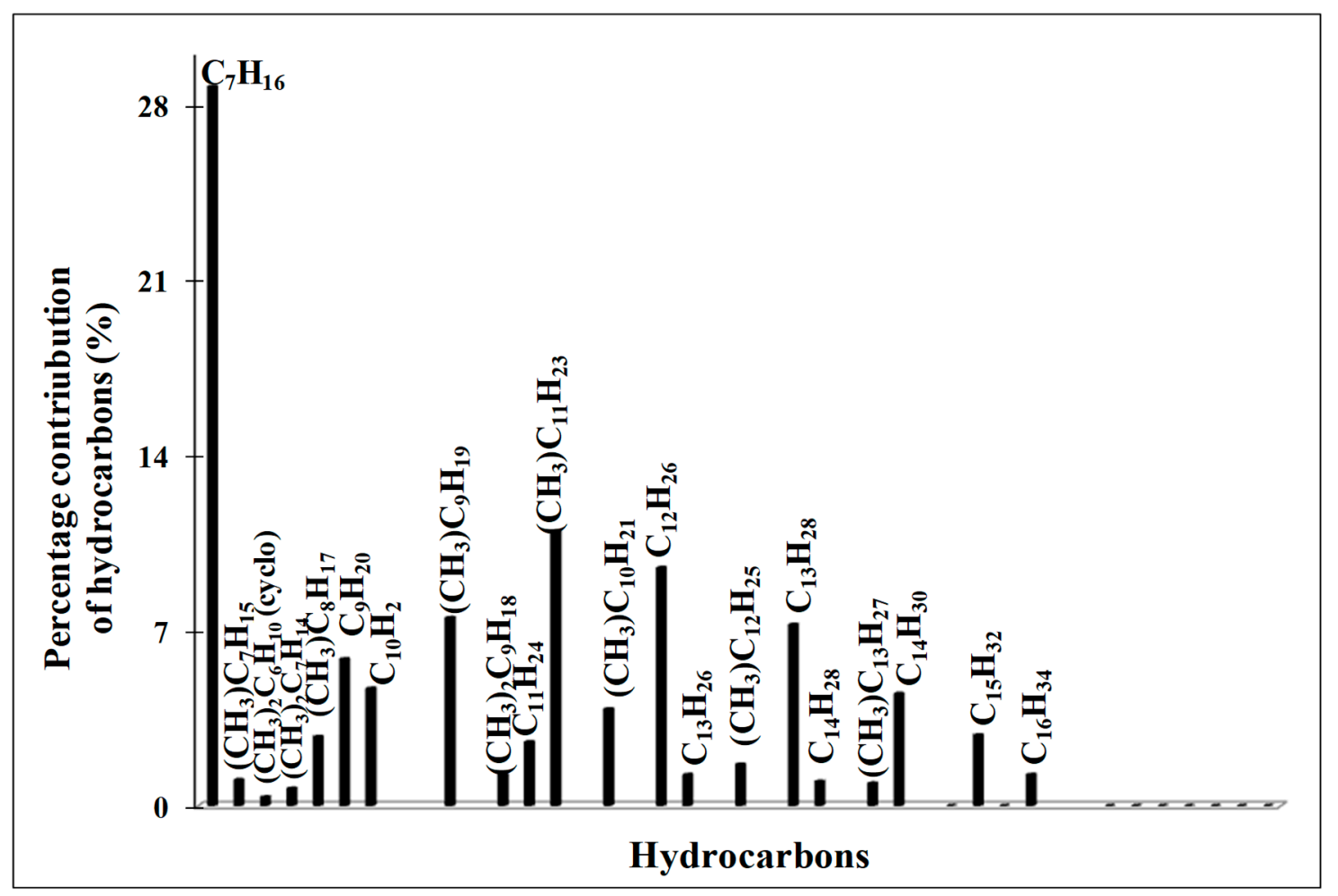

Figure 8. GC-MS analysis of liquid products obtained in FTS on Red-C-Co ${ }_{5.0} \mathrm{SiBEA}$ catalyst reduced at $500{ }^{\circ} \mathrm{C}$ in $100 \% \mathrm{H}_{2}$ flow.

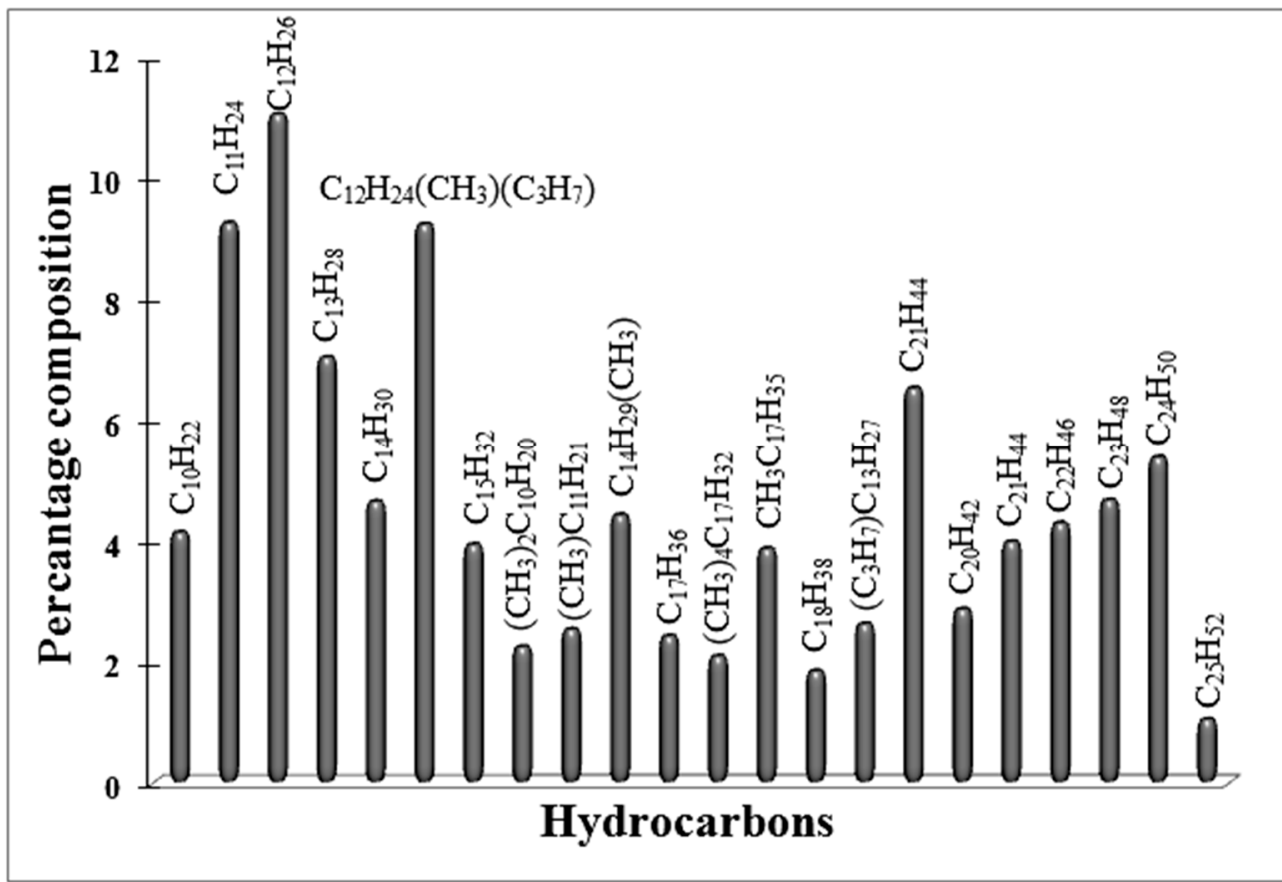

Figure 9. GC-MS analysis of liquid products obtained in FTS on Red-C-C ${ }_{5.0} \mathrm{SiBEA}$ catalyst reduced at $800{ }^{\circ} \mathrm{C}$ in $100 \% \mathrm{H}_{2}$ flow. 


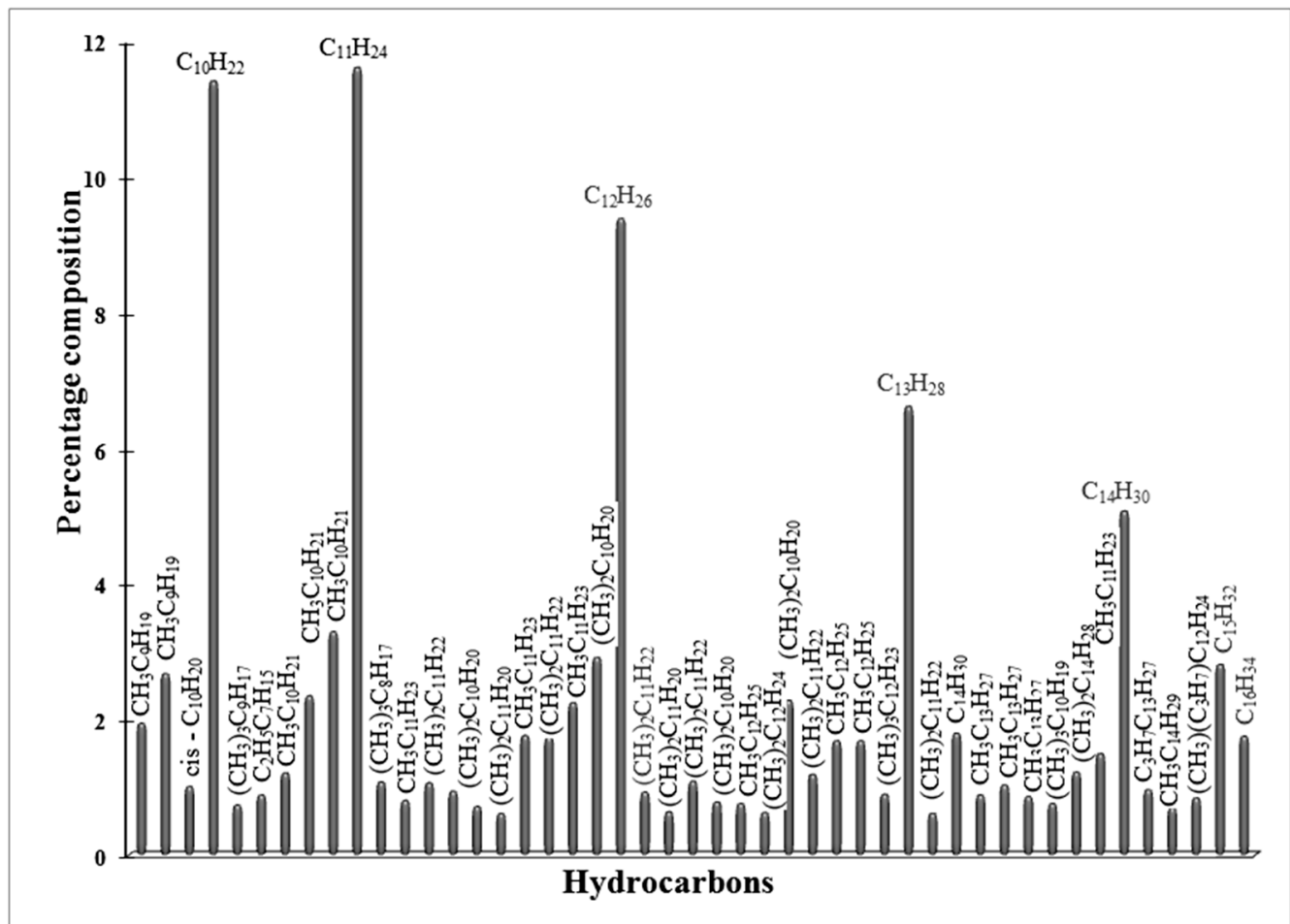

Figure 10. GC-MS analysis of liquid products obtained in FTS on Red-C-Co5.0 SiBEA catalyst reduced at $900{ }^{\circ} \mathrm{C}$ in $100 \% \mathrm{H}_{2}$ flow.

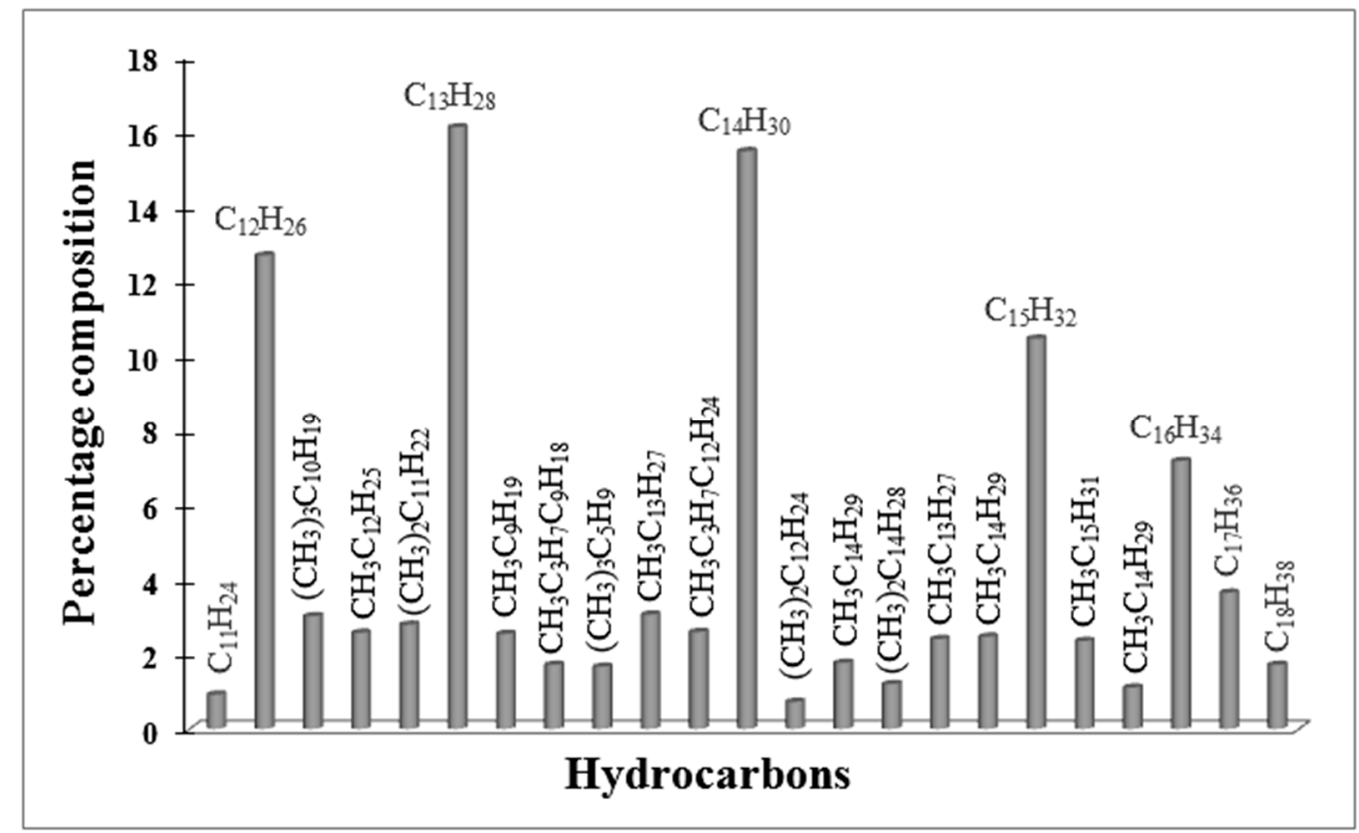

Figure 11. GC-MS analysis of liquid products obtained in FTS on Red-C-C ${ }_{5.0} \mathrm{SiBEA}$ catalyst reduced at $900{ }^{\circ} \mathrm{C}$ in $5 \% \mathrm{H}_{2}-95 \%$ Ar flow.

The ratio of isoalkanes/n-alkanes is 0.25 and the ratio of olefins/n-alkanes is 0.03 . The catalyst, reduced at $800{ }^{\circ} \mathrm{C}$ in a pure hydrogen flow, produced only isoalkanes $\left(\mathrm{C}_{10}-\mathrm{C}_{25}\right)$ and saturated n-alkanes with a ratio 0.39 , while with an increase of reduction temperature up to $900{ }^{\circ} \mathrm{C}$, the mentioned ratio raised to 0.95 (Figures 9 and 10).

The products obtained on Red-C- $\mathrm{CO}_{5.0} \mathrm{SiBEA}$ reduced at $900^{\circ} \mathrm{C}$ in $5 \%$ hydrogen consisting of liquid products $C_{11}-C_{18}$ are identified mainly as isoalkanes and n-alkanes with the ratio of 0.47 (Figure 11). 
It seems that the reduction temperature and reducing medium have significant impact on the liquid products formation. The increase of reduction temperature from 500 to $900{ }^{\circ} \mathrm{C}$ for $\mathrm{C}-\mathrm{Co}_{5.0} \mathrm{SiBEA}$ leads to isoalkanes and alkanes formation, with the carbon number in the chain from 10 to 25 of $C$. Moreover, the activation of $\mathrm{C}-\mathrm{Co}_{5.0} \mathrm{SiBEA}$ catalysts at $900{ }^{\circ} \mathrm{C}$ in a mixture of $5 \% \mathrm{H}_{2}-95 \%$ Ar for $1 \mathrm{~h}$ causes the increase of $\mathrm{CO}$ conversion up to $4.88 \%$, selectivity towards liquid hydrocarbons (mainly isoalkanes and n-alkanes with 11 to 18 carbon number in chains) up to $87.64 \%$ and decrease of selectivity towards $\mathrm{CH}_{4}$ to $12.27 \%$. This fact indicates that reduction at the highest temperature can improve the activity and mainly selectivity of cobalt BEA zeolite catalysts, despite the creation of the larger size of cobalt nanoparticles. However, the highest activity and selectivity have been obtained on Red-C-CO ${ }_{5.0} \mathrm{SiBEA}$ activated at $500{ }^{\circ} \mathrm{C}$ in pure hydrogen. It is probably related to the limited reduction of cobalt and presence of cobalt species in the zeolite framework, which can be responsible for shorter chains of hydrocarbons and olefins formation while longer chains of n-alkanes are formed on metallic cobalt nanoparticles. It is likely that isoalkanes are formed on acidic sites present in Red-C-Co ${ }_{5.0} \mathrm{SiBEA}$, reduced at $500{ }^{\circ} \mathrm{C}$. For this reason, the Red-C- $\mathrm{CO}_{5.0} \mathrm{SiBEA}$ reduced at $500{ }^{\circ} \mathrm{C}$ in pure hydrogen may be considered as bifunctional catalyst. It is also worthy to mention that an increase of temperature activation causes an increase of isoalkanes formation, and the same in the growing of the isoalkanes to n-alkanes ratio.

In the review of Zhnag et al. [30], the authors have mentioned that selectivity of cobalt zeolites catalysts depends on Si/Al ratio, acidity of the supports and porous size of support. Too small (narrower than $3 \mathrm{~nm}$ ) pores of supports are responsible for lower $\mathrm{CO}$ conversion and higher selectivity towards $\mathrm{CH}_{4}$. Authors concluded that acidity of the supports is the key factor in liquid hydrocarbons distribution, because if the primary liquid products formed possess access to acidic centers in zeolite they can be transformed into lighter hydrocarbons and iso-paraffins. They discussed the studies of Bessell [10], which reported that the most strongly acidic Co-ZSM-5 catalyst allowed to achieve the highest selectivity to gasoline-range hydrocarbons and the largest fraction of branched products. In the same work, it was also proved that the application of ZSM-12 in FTS, which possesses the largest pore channels $(0.57-0.61 \mathrm{~nm})$ but weaker acidity, led to formation of the highest fraction of gasoline in liquid hydrocarbons and the lowest fraction of n-paraffins. It seems that the formed primary hydrocarbons are cracked and isomerized into lighter hydrocarbons with more iso-paraffins in a secondary reaction occurred at the accessible zeolite acid sites [30].

We believe that we can modify and control FTS process and liquid hydrocarbon distribution by the changing of activation conditions and in this way the different kind of fuel can be obtained. Red-C-C $\mathrm{C}_{5.0} \mathrm{SiBEA}$ catalyst, considered in this work, depending on activation conditions can catalyze and allow the obtainment of gasoline (hydrocarbons from $\mathrm{C}_{5}-\mathrm{C}_{12}$, mainly n-alkanes and traces of unsaturated alkanes and aromatic hydrocarbons). When this catalyst is reduced at lower temperature, it allows to produce diesel fuel (n-alkanes, cycloalkanes, aromatic hydrocarbons). However, when it is reduced at higher temperatures, it allows to produce jet-fuel (aviation fuel; cycloalkanes, isoalkanes, aromatic hydrocarbons). It is very likely that the presence of the mainly Lewis acidic sites-and the high accessibility to the internal newly-created acidic centers of Red-C-C ${ }_{5.0} \mathrm{SiBEA}$ zeolite-are some of the key factors in the various kinds of liquid products formation.

In other work, the activity of cobalt supported on alumina modified meso-macroporous high silica (HS) in FTS was studied [31]. This type of cobalt catalysts achieved higher CO conversion but also higher selectivity towards methane (undesired product of FTS) and also lower selectivity towards paraffins in comparison to the catalyst described in this work. The authors explained this phenomenon by the lack of acidic sites [31]. In the case of our catalyst we have observed formation of isoalkanes with long carbon chain (even to 25 carbon atom number in chain, depending on activation conditions) and the selectivity towards desired liquid hydrocarbons was remarkably high. Moreover, in the same work it was found that prepared cobalt supported on hierarchical micro-meso-macroporous Beta zeolite possessing wealth of acidic sites achieved CO conversion of $41 \%$ (higher in comparison to Red-C-C ${ }_{5.0} \mathrm{SiBEA}$ ) and selectivity towards liquid hydrocarbons of $68.27 \%$, so lower than that obtained 
on Red-C-C ${ }_{5.0} \mathrm{SiBEA}$ reduced at $500{ }^{\circ} \mathrm{C}$ of $91 \%$. The authors explained the high selectivity towards isoalkanes and olefins by the presence of acidic sites. In their opinion the long-chain hydrocarbons are formed on the surface of metallic cobalt and their further transformation to isoalkanes takes place on acidic sites present close to cobalt. Moreover the author noted that the isomerization reaction can take place on Brønsted acid sites or results from the synergistic effect of working on both the Brønsted and Lewis acid sites [31]. We believe that in the case of Red-C-C ${ }_{5.0}$ SiBEA the cobalt localized in the zeolite framework created mainly the Lewis acid sites, which may be responsible for hydrocracking, aromatization and isomarization reactions. It is also well-known that the growth of hydrocarbons chains can occur on metallic cobalt nanoparticles, and after the primary formed hydrocarbons are transformed into lighter products on acidic sites present in the supports [30,31]. As mentioned above, the accessibilty to internal acidic sites is key factor in isoalkanes formation. In the case of Red-C-C ${ }_{5.0} \mathrm{SiBEA}$, the lower $\mathrm{CO}$ conversion could be a result of the small insufficient amount of cobalt nanoparticles located in the external space of the zeolite. However, the incorporation of the cobalt species into the zeolite framework can improve the selectivity towards liquid hydrocarbons of Red-C-C ${ }_{5.0}$ SiBEA, and these species may be responsible for the higher amount of isoalkanes and olefins formation.

\section{Materials and Methods}

\subsection{Samples Preparation}

$\mathrm{Co}_{5.0} \mathrm{SiBEA}$ and $\mathrm{CO}_{5.0} \mathrm{AlBEA}$ (where $\mathrm{x}=5.0 \mathrm{Co} \mathrm{wt} \%$ ) zeolites were obtained using the two-step postsynthesis preparation procedure and conventional wet impregnation, respectively $[19,20]$.

Tetraethylammonium BEA (TEABEA) zeolite was applied as parent zeolite. In the first, one part of TEABEA zeolite was calcined in air at $550{ }^{\circ} \mathrm{C}$ for $15 \mathrm{~h}$ in order to obtain an HAlBEA zeolite with $\mathrm{Si} / \mathrm{Al}$ ratio of 12.5. The $\mathrm{CO}_{5.0}$ AlBEA zeolites were obtained by impregnation of HAlBEA with $\mathrm{Co}\left(\mathrm{NO}_{3}\right)_{2}$ $6 \mathrm{H}_{2} \mathrm{O}$ solution (Sigma-Aldrich, St. Louis, MO, USA) at $\mathrm{pH}$ of 2.6 in aerobic conditions $[19,20]$. Then, during $2 \mathrm{~h}$ the suspensions were stirred at $80^{\circ} \mathrm{C}$ until evaporation of water. The obtained solids were dried in air $\left(80^{\circ} \mathrm{C}, 24 \mathrm{~h}\right)$ and then calcined in air $\left(500{ }^{\circ} \mathrm{C}, 3 \mathrm{~h}\right)$ and labelled $\mathrm{C}-\mathrm{Co}_{5.0}$ AlBEA.

The second portion of the TEABEA was treated in a nitric acid aqueous solution $\left(13 \mathrm{~mol} \mathrm{~L}^{-1}, 4 \mathrm{~h}\right.$, $80^{\circ} \mathrm{C}$ ) to obtain a silicious SiBEA with $\mathrm{Si} / \mathrm{Al}$ ratio of 1000 with vacant T-sites. The silicious SiBEA was separated by centrifugation, then washed with water and finally dried over $24 \mathrm{~h}$ at $80^{\circ} \mathrm{C}$. To introduce cobalt cations into the framework of SiBEA, $2 \mathrm{~g}$ of SiBEA was stirred in aerobic conditions $\left(25^{\circ} \mathrm{C}\right.$, $24 \mathrm{~h})$ in $200 \mathrm{~mL}$ of $\mathrm{Co}\left(\mathrm{NO}_{3}\right)_{2} 6 \mathrm{H}_{2} \mathrm{O}$ solution at $\mathrm{pH}$ of 2.4-2.6 [19,20]. Then, the suspension was stirred $\left(2 \mathrm{~h}, 80^{\circ} \mathrm{C}\right)$ up to evaporate water. The obtained solid was dried in air $\left(24 \mathrm{~h}, 80^{\circ} \mathrm{C}\right)$ and labelled as $\mathrm{Co}_{5.0} \mathrm{SiBEA}$. Then, the solid was calcined in air $\left(3 \mathrm{~h}, 500^{\circ} \mathrm{C}\right)$ and labelled $\mathrm{C}-\mathrm{Co}_{5.0} \mathrm{SiBEA}$.

$\mathrm{C}-\mathrm{Co}_{5.0} \mathrm{SiBEA}$ and $\mathrm{C}-\mathrm{Co}_{5.0} \mathrm{AlBEA}$ were reduced in situ under atmospheric pressure in flow of $100 \% \mathrm{H}_{2}$ or $95 \% \mathrm{H}_{2}-5 \%$ Ar at 500,800 or $900{ }^{\circ} \mathrm{C}$ for $1 \mathrm{~h}$. The obtained catalysts were labelled as Red-C-Co ${ }_{5.0}$ SiBEA and Red-C-Co ${ }_{5.0}$ AlBEA.

\subsection{Samples Characterization}

From the point of view of catalytic activity, an important property of catalysts is the size of the specific surface and porosity. These two features of the catalyst affect not only its activity and selectivity but also, they have impact on heat and mass transport as well as resistance to cocking phenomenon. The specific surface area and pore size of the tested catalysts were determined by the method of low temperature nitrogen adsorption (BET). The SSA and PV of catalysts and their supports were measured with automatic sorptometer Micromeritics ASAP 2020 V3.05 G (surface area and porosity analyzer). The solids were prepared at $300^{\circ} \mathrm{C}$ upon evacuation during $2 \mathrm{~h}$ and the low temperature $\mathrm{N}_{2}$ adsorption-desorption measurements were performed.

The cobalt content in the obtained samples as well as the $\mathrm{Si} / \mathrm{Al}$ ratio were determined at room temperature by X-ray fluorescence (XRF) (SPECTRO X-LabPro, Kleve, Germany). X-ray fluorescence 
spectroscopy (XRF-X-ray fluorescence spectroscopy) belongs to the non-destructive analytical methods and is one of the most used techniques in determining the elemental composition of analyzed substances. By simultaneously measuring the fluorescence of each element, the XRF analyzer allows to accurate measure of the composition of the material and to define the concentration of each element. This method was used to determining of the elemental composition of prepared samples, very quickly and very accurately. As prepared $\mathrm{C}_{5.0} \mathrm{AlBEA}$ and $\mathrm{Co}_{5.0} \mathrm{SiBEA}$ samples were analyzed without high temperature heat treatment.

The XRD study was performed on a PANalytical X'Pert Pro diffractometer (Malvern Panalytical Ltd., Malvern, United Kingdom) using $\mathrm{Cu} \mathrm{K}_{\alpha}$ radiation $(\lambda=154.05 \mathrm{pm})$ in $2 \theta$ range of $5-90^{\circ}$. The most common use of X-ray diffraction (XRD) is the analysis of the phase composition of catalytic systems. This analysis is based on the Bragg equation which allows to determine the distance of lattice planes " $\mathrm{d}$ " in the crystal. These distances are characteristic of a given crystalline substance. The analysis of the obtained data was performed using the X'Pert HighScore Plus software and was interpreted based on the 2 theta angle values determined using the JCPDS (Joint Committee on Power Diffraction Standards) tables.

In the temperature-programmed methods, a sample is in a controlled atmosphere (inert, oxidizing or reducing) and it is given to a linearly programmed temperature rise. In this way, various reactions occurring on the sample surface can be observed, e.g., adsorption processes-desorption or susceptibility to reduction of metal oxide phases present in the catalytic system. In the temperature-programmed reduction technique, the reducing gas (hydrogen, carbon monoxide) flows through the sample, and the reduction rate is recorded as a change in the reducing gas content or by analyzing the reduction product at the reactor outlet by gas chromatography or mass spectrometry. TPR profiles show the successive stages of reduction of oxide phases and allow to obtain information about interactions between the carrier and the active phase. The TPR- $\mathrm{H}_{2}$ patterns were obtained on an automatic TPR system (AMI-1) in the temperature range between 25 and $900{ }^{\circ} \mathrm{C}$, using $\left(5 \% \mathrm{H}_{2}-95 \%\right.$ Ar flow of $40 \mathrm{~mL} \mathrm{~min}^{-1}$ (Air Products Ltd., Poland). Thermal conductivity detector (TCD) allows monitoring $\mathrm{H}_{2}$ consumption (Altamira Instruments, Pittsburgh, USA).

Time-of-flight secondary ion mass spectrometry (ToF-SIMS) is used to characterize solid surfaces and allows for determination of their composition. In this work, the ToF-SIMS technique was applied to the analysis of the surface of the obtained cobalt zeolite catalysts to confirm the presence of silicates and aluminosilicates The ToF-SIMS experiments were conducted using an ION-TOF GmbH instrument (TOF-SIMS IV) equipped with $25 \mathrm{kV}$ pulsed $\mathrm{Bi}_{3}{ }^{+}$primary ion gun in the static mode (primary ion dose about $3 \times 10^{10}$ ion $\mathrm{cm}^{-2}$ ). The analyzed area corresponds to a square of $500 \times 500 \mu \mathrm{m}$. For each sample, three spectra were collected. Before each experiment the samples were pressed into pellets and attached to the sample holder using a double-sided tape. For charge compensation, a pulsed electron flood gun was used.

After TPR experiment, the crystal morphology, and the size of particles of Red-C-C $0_{5.0} \mathrm{AlBEA}$ and Red-C-C 5. $_{.0}$ SiBEA samples were identified by TEM (JEOL JEM 2100 FEG microscope, Tokyo, Japan). In this work, the TEM technique was used for observation of the degree of ordering of the catalyst structure and its defect and determining the size of metal nanoparticles.

A tungsten gun and $100 \mathrm{kV}$ voltage were used in the tests. Measurements were made for carriers and selected samples of cobalt systems after reduction.

The technique of temperature-programmed desorption is one of the oldest and the most used temperature programmed methods. Ammonia, pyridine or quinoline is used to determine the acidity of zeolites. Based on the detected TPD profiles of molecules-probes, the determination of the number of acid centers and calculating of their relative power is possible. In this work, temperature programmed ammonia desorption (TPD- $\mathrm{NH}_{3}$ ) using the flow method was used to determine the acidity of the tested catalytic systems. TPD detection was carried out using a TCD thermal conductivity detector (Altamira Instruments, Pittsburgh, USA). The TPD- $\mathrm{NH}_{3}$ were done in a quartz reactor using gaseous ammoniac. $\mathrm{NH}_{3}$ was adsorbed on zeolite catalysts, dried at $500{ }^{\circ} \mathrm{C}$ in He flow for $30 \mathrm{~min}$ at $100{ }^{\circ} \mathrm{C}$ 
for $10 \mathrm{~min}$ in flowing He. The TPD of $\mathrm{NH}_{3}$ was carried out in the temperature range $25-500{ }^{\circ} \mathrm{C}$, after removing physisorbed ammonium from the catalyst.

In FTIR spectroscopy, energy changes occur at transitions between quantized levels of oscillatory and rotational energy of groups of atoms in the area of wavenumbers of $4000-400 \mathrm{~cm}^{-1}$ which occur while the vibration of atoms in the molecule is accompanied by a change in dipole moment. In heterogeneous catalyst studies, IR spectroscopy is used to identify the surface groups present in the catalyst and also for determination of the structure of the molecules adsorbed on the surface, which makes it possible to determine, for example, the acidity of the catalysts and to distinguish between Brønsted and Lewis acid centers. The advantage of the method is the possibility of conducting measurements in a controlled atmosphere and temperature. It is a very convenient technique for studying the distribution of acid centers. In this work, FTIR spectroscopy was used to study the acidity of the obtained systems in which pyridine was used as the probe. The FTIR spectra were measured on Bruker Vector 22 spectrometer containing DTGS detector with resolution of $2.0 \mathrm{~cm}^{-1}$. For each FTIR spectra, 128 scans have been performed. The solids were pressed at $\sim 0.2$ tons $\mathrm{cm}^{-2}$ into thin wafers of ca. $10 \mathrm{mg} \mathrm{cm}^{-2}$. Then the wafers were placed inside the IR cell. The wafers were calcined at $450{ }^{\circ} \mathrm{C}$ for $3 \mathrm{~h}$ in $\mathrm{O}_{2}(16 \mathrm{kPa})$ and then outgassed at $300^{\circ} \mathrm{C}\left(10^{-3} \mathrm{~Pa}\right)$ for $1 \mathrm{~h}$. The wafers were contacted at room temperature with gaseous pyridine $(133 \mathrm{~Pa})$ via a separate cell contacting liquid pyridine. After saturation with pyridine, the samples were outgassed at $150{ }^{\circ} \mathrm{C}\left(10^{-3} \mathrm{~Pa}\right)$. FTIR spectra were recorded at room temperature in the range of $4000-400 \mathrm{~cm}^{-1}$.

\subsection{Catalytic Tests}

The FTS tests were performed in a fixed bed reactor. A mixture of $\mathrm{H}_{2}$ and $\mathrm{CO}$ with molar ratio of $2 / 1$ and flow of reagents of $60 \mathrm{~mL} \mathrm{~min}^{-1}$ were used. The FTS tests were performed at $260{ }^{\circ} \mathrm{C}$ (under $30 \mathrm{~atm}$ ) and gaseous reagents were analyzed by GC gas chromatograph (Shimadzu GC-14; Shimadzu Corporation, Duisburg, Germany) ) with TCD detector. Two columns were applied, one measuring Carbosphere 7A and the second the comparative molecular sieves 7B. GC measurements were realized in the following conditions: column's temperature $-45^{\circ} \mathrm{C}$, detector's temperature $-120^{\circ} \mathrm{C}$, detector's current- $100 \mathrm{~mA}$; carried gas-He. The zeolite catalysts were reduced in situ in atmospheric pressure in a flow of $100 \% \mathrm{H}_{2}$ or $95 \% \mathrm{H}_{2}-5 \%$ Ar gas mixture at $500{ }^{\circ} \mathrm{C}$ for $1 \mathrm{~h}$. Th GC-MS coupled technique was used for analyzing the liquid products. A gas chromatograph (6890N Network GC) equipped with a capillary column HP-5MS (Agilent Technology) was coupled with a quadrupole mass spectrometer (5973 Network Mass Selective Detector). The liquid products were concentrated by SPE method on octadecyl columns $\mathrm{C} 18$. Each of the columns was preconditioned with $2 \mathrm{~mL}$ of $\mathrm{n}$-hexane before extraction. Then, liquid products were injected on the column and it was washed with $2 \mathrm{~mL}$ of n-hexane. GC-MS analysis was performed in helium flow $\left(0.7 \mathrm{~mL} \mathrm{~min}^{-1}\right)$ in a temperature between 60 and $280^{\circ} \mathrm{C}$ with increase linear temperature of $10{ }^{\circ} \mathrm{C} \mathrm{min}-1$. The volume of the analyzed sample was 1 $\mathrm{mm}^{3}$.

The analysis of $\mathrm{CO}$ conversion $\left(\mathrm{K}_{\mathrm{CO}}\right)$ and selectivity to $\mathrm{CO}_{2}\left(\mathrm{~S}_{\mathrm{CO} 2}\right), \mathrm{CH}_{4}\left(\mathrm{~S}_{\mathrm{CH} 4}\right)$ and liquid products $\left(\mathrm{S}_{\mathrm{LP}}\right)$ were obtained as described in our previous work [1,24]:

$$
\begin{gathered}
\mathrm{K}_{\mathrm{co}}=\left(\left(\mathrm{S}_{\mathrm{coin}}-\mathrm{S}_{\mathrm{COari}}\right) / \mathrm{S}_{\mathrm{COin}}\right) \times 100 \% \\
\mathrm{~S}_{\mathrm{CH} 4}=\left(\left(\mathrm{X}_{\mathrm{CH} 4} \times 100 \%\right) / \mathrm{X}_{\mathrm{CH} 4 \text { out }}\right) / \mathrm{F} \\
\mathrm{X}_{\mathrm{CH} 4 \text { out }}=\left(\mathrm{X}_{\mathrm{CH} 4 \mathrm{~s}} \times \mathrm{K}_{\mathrm{CO}}\right) / 100 \% \\
\mathrm{~S}_{\mathrm{CO} 2 \text { out }}=\left(\left(\mathrm{X}_{\mathrm{CO} 2 \mathrm{i}} \times 100 \%\right) / \mathrm{X}_{\mathrm{CO} 2 \text { out }}\right) / \mathrm{F} \\
\mathrm{X}_{\mathrm{CO} 2 \text { out }}=\left(\mathrm{X}_{\mathrm{CO} 2 \mathrm{~s}} \times \mathrm{K}_{\mathrm{CO}}\right) / 100 \% \\
\mathrm{~F}=\mathrm{S}_{\mathrm{Ari}} / \mathrm{S}_{\mathrm{Ars}}
\end{gathered}
$$


where: $\mathrm{K}_{\mathrm{CO}}-\mathrm{CO}$ conversion of $\mathrm{CO}$; $\mathrm{S}_{\mathrm{CO}}-$ the area of the $\mathrm{CO}$ peak before reaction; $\mathrm{S}_{\mathrm{COari}}-$ the area of the $\mathrm{CO}$ peak after reaction; $\mathrm{S}_{\mathrm{CH} 4}-\mathrm{CH} 4$ selectivity; $\mathrm{S}_{\mathrm{CO} 2}-\mathrm{CO}_{2}$ selectivity; $\mathrm{X}_{\mathrm{CH} 4 \mathrm{i}}$ - the area of the peak of obtained $\mathrm{CH}_{4} ; \mathrm{X}_{\mathrm{CO} 2 \mathrm{i}}$ - the area of the peak of obtained $\mathrm{CO}_{2} ; \mathrm{X}_{\mathrm{CH} 4 \text { out }}$-the area of the theoretical $\mathrm{CH}_{4}$ peak (when all $\mathrm{CO}$ is converted to $\mathrm{CH}_{4}$ ); $\mathrm{X}_{\mathrm{CO} \text { out }}$ - the area of the theoretical $\mathrm{CO}_{2}$ peak (when all $\mathrm{CO}$ is converted to $\mathrm{CO}_{2}$ ); $\mathrm{X}_{\mathrm{CH} 4 \mathrm{~s}}$ - the area of the standard $\mathrm{CH}_{4}$ (when only $\mathrm{CH}_{4}$ is tested); $\mathrm{X}_{\mathrm{CO} 2 \mathrm{~s}}$ - the area of the standard $\mathrm{CO}_{2}$ (when only $\mathrm{CO}_{2}$ is tested); $\mathrm{F}$ - contraction coefficient; $\mathrm{S}_{\mathrm{Ari}}$ - the the area of the Ar peak during reaction; $\mathrm{S}_{\mathrm{Ar} \mathrm{s}}$ - the area of the Ar peak before reaction.

The $\mathrm{C}_{2}-\mathrm{C}_{6}$ hydrocarbons were not determined in GC analysis. The selectivity to liquid products were obtained from following equation:

$$
\mathrm{S}_{\mathrm{LP}}=100-\left(\mathrm{S}_{\mathrm{CH} 4}+\mathrm{S}_{\mathrm{CO} 2}\right)
$$

\section{Conclusions}

The Red-C-CO ${ }_{5.0}$ AlBEA and Red-C-C0 ${ }_{5.0}$ SiBEA catalyst systems obtained in this work by two different preparation procedures with various physicochemical properties were tested in Fischer-Tropsch reaction. Among the studied catalysts the most active catalyst was Red-C-Co ${ }_{5.0} \mathrm{SiBEA}$ reduced at $500{ }^{\circ} \mathrm{C}$ in pure hydrogen, which presented selectivity to liquid products of $91 \%$ containing mainly $\mathrm{C}_{7}-\mathrm{C}_{16} \mathrm{n}$-alkanes and isoalkanes as well as a small amount of olefins with CO conversion of about $11 \%$. The Red-C-Co ${ }_{5.0}$ AlBEA catalysts were not active in the Fischer-Tropsch synthesis.

It showed that removal of aluminum from BEA zeolite in the first step of postsynthesis preparation procedure played a key role in the preparation of an efficient catalyst for FTS, as it allows the incorporation of Co ions in the framework of siliceous SiBEA as tetrahedral Co(II) strongly bonded to the $\mathrm{C}-\mathrm{CO}_{5.0} \mathrm{SiBEA}$ structure, and then upon reduction in pure hydrogen or in hydrogen-argon mixture $\left(5 \% \mathrm{H}_{2}-95 \%\right.$ Ar) the obtainment of cobalt nanoparticles of small size and well dispersed in the zeolite structure.

It was shown that the increase of the reduction temperature from $500{ }^{\circ} \mathrm{C}$ to $800{ }^{\circ} \mathrm{C}$ and then to $900{ }^{\circ} \mathrm{C}$ caused two times lower $\mathrm{CO}$ conversion and drop of the selectivity towards liquid products (up to $62 \%-88 \%$ ) for the Red-C-Co ${ }_{5.0} \mathrm{SiBEA}$ catalyst.

The n-alkanes and isoalkanes were the main liquid products identified in FTS on Red-C-Co ${ }_{5.0}$ SiBEA catalyst.

Author Contributions: Conceptualization, K.A.C., S.D. and J.R.; methodology, K.A.C., S.D. and J.R.; software, validation, formal analysis, investigation, resources and data curation, K.A.C., T.O.; BET, XRD, TPR-H2, TPD-NH3, catalytic performance, K.A.C., P.M.; ToF-SIMS, J.G.; GC-MS analysis, K.A.C.; FTIR, T.O.; TEM-EDS, S.C.; writing-original draft preparation, K.A.C. and S.D.; writing-review and editing, K.A.C. and S.D.; visualization, K.A.C. and S.D.; supervision, S.D., J.R. and M.I.S.; project administration, K.A.C.; funding acquisition, K.A.C. All authors agreed to the published version of the manuscript.

Funding: National Science Center (Poland) funded this research Grant No. N N209 762140) and Dean of Chemistry Department Grants for Young Researchers (Grant 2014, Grant 2015).

Conflicts of Interest: The authors declare no conflict of interest. The funders had no role in the design of the study; in the collection, analyses, or interpretation of data; in the writing of the manuscript, or in the decision to publish the results.

\section{References}

1. Chalupka, K.; Casale, S.; Żurawicz, E.; Rynkowski, J.; Dzwigaj, S. The remarkable effect of the preparation procedure on the catalytic activity of CoBEA zeolites in the Fischer-Tropsch synthesis. Microporous Mesoporous Mater. 2015, 211, 9-18. [CrossRef]

2. Tsakoumis, N.E.; Rønning, M.; Borg, Ø.; Rytter, E.; Holmen, A. Deactivation of cobalt based Fischer-Tropsch catalysts: A review. Catal. Today 2010, 154, 162-182. [CrossRef]

3. Weststrate, C.; Van De Loosdrecht, J.; Niemantsverdriet, J.W. Spectroscopic insights into cobalt-catalyzed Fischer-Tropsch synthesis: A review of the carbon monoxide interaction with single crystalline surfaces of cobalt. J. Catal. 2016, 342, 1-16. [CrossRef] 
4. Concepción, P.; López, C.; Martínez, A.; Puntes, V. Characterization and catalytic properties of cobalt supported on delaminated ITQ-6 and ITQ-2 zeolites for the Fischer-Tropsch synthesis reaction. J. Catal. 2004, 228, 321-332. [CrossRef]

5. Pour, A.N.; Zamani, Y.; Tavasoli, A.; Shahri, S.M.K.; Taheri, S.A. Study on products distribution of iron and iron-zeolite catalysts in Fischer-Tropsch synthesis. Fuel 2008, 87, 2004-2012. [CrossRef]

6. Martínez, A.; Lopez, C. The influence of ZSM-5 zeolite composition and crystal size on the in situ conversion of Fischer-Tropsch products over hybrid catalysts. Appl. Catal. A Gen. 2005, 294, 251-259. [CrossRef]

7. Tang, Q.; Wang, Y.; Zhang, Q.; Wan, H. Preparation of metallic cobalt inside NaY zeolite with high catalytic activity in Fischer-Tropsch synthesis. Catal. Commun. 2003, 4, 253-258. [CrossRef]

8. Liu, Z.-W.; Li, X.-H.; Asami, K.; Fujimoto, K. Iso-paraffins synthesis from modified Fischer-Tropsch reaction-Insights into Pd/beta and Pt/beta catalysts. Catal. Today 2005, 104, 41-47. [CrossRef]

9. Li, X.; He, J.; Meng, M.; Yoneyama, Y.; Tsubaki, N. One-step synthesis of H- $\beta$ zeolite-enwrapped Co/Al2O3 Fischer-Tropsch catalyst with high spatial selectivity. J. Catal. 2009, 265, 26-34. [CrossRef]

10. Bessell, S. Investigation of bifunctional zeolite supported cobalt Fischer-Tropsch catalysts. Appl. Catal. A: Gen. 1995, 126, 235-244. [CrossRef]

11. Sadek, R.; Chalupka, K.; Mierczynski, P.; Rynkowski, J.; Gurgul, J.; Dzwigaj, S. Cobalt Based Catalysts Supported on Two Kinds of Beta Zeolite for Application in Fischer-Tropsch Synthesis. Catal. 2019, 9, 497. [CrossRef]

12. Roberge, D.M.; Hausmann, H.; Holderich, W.F. Dealumination of zeolite beta by acid leaching: A new insight with two-dimensional multi-quantum and cross polarization 27Al MAS NMR. Phys. Chem. Chem. Phys. 2002, 4, 3128-3135. [CrossRef]

13. Bernasconi, S.; Van Bokhoven, J.A.; Krumeich, F.; Pirngruber, G.D.; Prins, R. Formation of mesopores in zeolite beta by steaming: A secondary pore channel system in the plane. Microporous Mesoporous Mater. 2003, 66, 21-26. [CrossRef]

14. Lenarda, M.; Da Ros, M.; Casagrande, M.; Storaro, L.; Ganzerla, R. Post-synthetic thermal and chemical treatments of H-BEA zeolite: Effects on the catalytic activity. Inorganica Chim. Acta 2003, 349, 195-202. [CrossRef]

15. Marques, J.; Gener, I.; Ayrault, P.; Bordado, J.; Lopes, J.; Ribeiro, F.R.; Guisnet, M. Infrared spectroscopic study of the acid properties of dealuminated BEA zeolites. Microporous Mesoporous Mater. 2003, 60, 251-262. [CrossRef]

16. Omegna, A.; Vasic, M.; Van Bokhoven, J.A.; Pirngruber, G.D.; Prins, R. Dealumination and realumination of microcrystalline zeolite beta: An XRD, FTIR and quantitative multinuclear (MQ) MAS NMR study. Phys. Chem. Chem. Phys. 2004, 6, 447. [CrossRef]

17. Oumi, Y.; Mizuno, R.; Azuma, K.; Nawata, S.; Fukushima, T.; Uozumi, T.; Sano, T. Riversibility of dealumination-realumination process of BEA zeolite. Microporous Mesoporous Mater. 2001, 49, 103-109. [CrossRef]

18. Hajjar, R.; Millot, Y.; Man, P.P.; Che, M.; Dzwigaj, S. Two Kinds of Framework Al Sites Studied in BEA Zeolite by X-ray Diffraction, Fourier Transform Infrared Spectroscopy, NMR Techniques, and V Probe. J. Phys. Chem. C 2008, 112, 20167-20175. [CrossRef]

19. Janas, J.; Machej, T.; Gurgul, J.; Socha, R.; Che, M.; Dzwigaj, S. Effect of Co content on the catalytic activity of CoSiBEA zeolite in the selective catalytic reduction of $\mathrm{NO}$ with ethanol: Nature of the cobalt species. Appl. Catal. B Environ. 2007, 75, 239-248. [CrossRef]

20. Janas, J.; Shishido, T.; Che, M.; Dzwigaj, S. Role of tetrahedral Co(II) sites of CoSiBEA zeolite in the selective catalytic reduction of NO: XRD, UV-vis, XAS and catalysis study. Appl. Catal. B Environ. 2009, 89, 196-203. [CrossRef]

21. Camiloti, A.; Jahn, S.; Velasco, N.; Moura, L.; Cardoso, D. Acidity of Beta zeolite determined by TPD of ammonia and ethylbenzene disproportionation. Appl. Catal. A Gen. 1999, 182, 107-113. [CrossRef]

22. Camblor, M.; Corma, A.; Pérez-Pariente, J. Synthesis of titanoaluminosilicates isomorphous to zeolite Beta, active as oxidation catalysts. Zeolites 1993, 13, 82-87. [CrossRef]

23. Dzwigaj, S.; Che, M. Incorporation of Co(II) in Dealuminated BEA Zeolite at Lattice Tetrahedral Sites Evidenced by XRD, FTIR, Diffuse Reflectance UV-Vis, EPR, and TPR. J. Phys. Chem. B 2006, 110, 12490-12493. [CrossRef] [PubMed] 
24. Chalupka, K.; Maniukiewicz, W.; Mierczynski, P.; Maniecki, T.; Rynkowski, J.; Dzwigaj, S. The catalytic activity of Fe-containing SiBEA zeolites in Fischer-Tropsch synthesis. Catal. Today 2015, 257, 117-121. [CrossRef]

25. Xiao, F.-S.; Wang, L.; Yin, C.; Lin, K.; Di, Y.; Li, J.; Xu, R.; Su, D.S.; Schlögl, R.; Yokoi, T.; et al. Catalytic Properties of Hierarchical Mesoporous Zeolites Templated with a Mixture of Small Organic Ammonium Salts and Mesoscale Cationic Polymers. Angew. Chem. Int. Ed. 2006, 45, 3090-3093. [CrossRef] [PubMed]

26. Savost'Yanov, A.P.; Narochnyi, G.B.; Yakovenko, R.E.; Saliev, A.N.; Sulima, S.I.; Zubkov, I.; Nekroenko, S.V.; Mitchenko, S. Synthesis of Low-Pour-Point Diesel Fuel in the Presence of a Composite Cobalt-Containing Catalyst. Pet. Chem. 2017, 57, 1186-1189. [CrossRef]

27. Sadek, R.; Chalupka, K.; Mierczynski, P.; Rynkowski, J.; Millot, Y.; Valentin, L.; Casale, S.; Dzwigaj, S. Fischer-Tropsch reaction on Co-containing microporous and mesoporous Beta zeolite catalysts: The effect of porous size and acidity. Catal. Today 2019. [CrossRef]

28. Emeis, C. Determination of Integrated Molar Extinction Coefficients for Infrared Absorption Bands of Pyridine Adsorbed on Solid Acid Catalysts. J. Catal. 1993, 141, 347-354. [CrossRef]

29. Park, J.-Y.; Lee, Y.-J.; Karandikar, P.R.; Jun, K.-W.; Ha, K.-S.; Park, H.-G. Fischer-Tropsch catalysts deposited with size-controlled $\mathrm{Co} 3 \mathrm{O} 4$ nanocrystals: Effect of Co particle size on catalytic activity and stability. Appl. Catal. A: Gen. 2012, 411, 15-23. [CrossRef]

30. Zhang, Q.; Kang, J.; Wang, Y. Development of Novel Catalysts for Fischer-Tropsch Synthesis: Tuning the Product Selectivity. Chem CatChem 2010, 2, 1030-1058. [CrossRef]

31. Li, H.; Hou, B.; Wang, J.; Qin, C.; Zhong, M.; Huang, X.; Jia, L.; Li, D. Direct conversion of syngas to isoparaffins over hierarchical beta zeolite supported cobalt catalyst for Fischer-Tropsch synthesis. Mol. Catal. 2018, 459, 106-112. [CrossRef]

(C) 2020 by the authors. Licensee MDPI, Basel, Switzerland. This article is an open access article distributed under the terms and conditions of the Creative Commons Attribution (CC BY) license (http://creativecommons.org/licenses/by/4.0/). 